\title{
Caregiver-Child Verbal Interactions in Child Care: A Buffer against Poor Language Outcomes when Maternal Language Input is Less
}

\author{
Lynne Vernon-Feagans, \\ The University of North Carolina
}

Mary E. Bratsch-Hines, and

The University of North Carolina

The Family Life Project Key Investigators

\begin{abstract}
Recent research has suggested that high quality child care can buffer young children against poorer cognitive and language outcomes when they are at risk for poorer language and readiness skills. Most of this research measured the quality of parenting and the quality of the child care with global observational measures or rating scales that did not specify the exact maternal or caregiver behaviors that might be causally implicated in the buffering of these children from poor outcomes. The current study examined the actual language by the mother to her child in the home and the verbal interactions between the caregiver and child in the child care setting that might be implicated in the buffering effect of high quality childcare. The sample included 433 rural children from the Family Life Project who were in child care at 36 months of age. Even after controlling for a variety of covariates, including maternal education, income, race, child previous skill, child care type, the overall quality of the home and quality of the child care environment; observed positive caregiver-child verbal interactions in the child care setting interacted with the maternal language complexity and diversity in predicting children's language development. Caregiver-child positive verbal interactions appeared to buffer children from poor language outcomes concurrently and two years later if children came from homes where observed maternal language complexity and diversity during a picture book task was less.
\end{abstract}

\section{Keywords}

Children's language; Child care language interactions; Maternal language input; Rural; Child care quality

\footnotetext{
(C) 2013 Elsevier Inc. All rights reserved.

Please direct correspondence to Lynne Vernon-Feagans, 301K Peabody Hall, \#3500, Chapel Hill, NC 27599, USA. Tele: 919-843-5623. Fax: 919 962-1533. lynnevf@email.unc.edu.

*The Family Life Project (FLP) Key Investigators include Lynne Vernon Feagans, The University of North Carolina; Martha Cox, The University of North Carolina; Clancy Blair, The Pennsylvania State University; Peg Burchinal, The University of North Carolina; Linda Burton, Duke University; Keith Crnic, The Arizona State University; Ann Crouter, The Pennsylvania State University; Patricia Garrett-Peters, The University of North Carolina; Mark Greenberg, The Pennsylvania State University; Stephanie Lanza, The Pennsylvania State University; Roger Mills-Koonce, The University of North Carolina; Emily Werner, The Pennsylvania State University and Michael Willoughby, The University of North Carolina.

Publisher's Disclaimer: This is a PDF file of an unedited manuscript that has been accepted for publication. As a service to our customers we are providing this early version of the manuscript. The manuscript will undergo copyediting, typesetting, and review of the resulting proof before it is published in its final citable form. Please note that during the production process errors may be discovered which could affect the content, and all legal disclaimers that apply to the journal pertain.
} 


\section{Caregiver-Child Verbal Interactions in Child Care: A Buffer against Poor Language Outcomes When Maternal Language Input is Less}

Previous research has suggested that both the quality of early parenting and the quality of early child care are important in the prediction of children's later language and school readiness skills (Crosnoe et al., 2010; NICHD ECCRN, 2000; 2001; 2005; 2006). In particular, some studies have speculated that the language scaffolding used by parents and caregivers might be the critical aspect of high quality care giving that is linked to better child language and school readiness (Burchinal, Peisner-Feinberg, Bryant, \& Clifford, 2000; Cabell et al., 2011; Crosnoe et al., 2010; NICHD ECCRN, 2000, 2005; Peisner-Feinberg et al., 2001, Piasta et al., 2012; Vandell et al., 2010). Particularly relevant for the current paper have been recent findings suggesting that children at risk may benefit more from highquality child care than children not at risk in predicting children's concurrent and later academic success (Dearing, McCartney, \& Taylor, 2009; McCartney \& Berry, 2009; McCartney, Dearing, Taylor \& Bub, 2007). Much of this work to date on the buffering effect of high-quality child care has only speculated that the language provided by the caregiver in high-quality child care settings might be the most important factor in buffering children from poorer outcomes. The researchers have argued that children from impoverished backgrounds or children with low readiness skills do not receive parental language input at home that would promote school readiness (Burchinal et al., 2000; Hart \& Risley, 1995; Hoff, 2003; NICHD ECCRN, 2000), suggesting that rich language in the child care setting could therefore help buffer these children from risk.

The current study extends the findings of the previous work by examining both the language used by mothers in the home with their young children while also examining the language interactions between the caregiver and child in the child care setting. By measuring both the language at home and in the child care setting, this study can examine the role of the interaction between language in the home and in child care in predicting children's language outcomes. This study is interested in understanding if high levels of caregiver-child verbal interactions in child care would benefit children who come from homes with lower levels of maternal language stimulation. By contrast, caregiver-child verbal interactions in child care might not benefit children as much who come from homes with higher levels of maternal language stimulation. We call this possible positive interaction buffering. In examining the possible buffering effects of the specific caregiver-child verbal interactions, this study will more stringently test whether buffering exists by controlling for a host of socioeconomic variables, such as income and maternal education, as well as controlling for earlier child language and cognition skills, structural child care variables, the overall quality of the home environment, and the overall quality of the child care environment. In the current study, after we control for these covariates, we hypothesize that in the presence of lower levels of mother-child language interactions in the home, caregiver-child verbal interactions in the child care setting will buffer children from lower language development scores, both concurrently and for subsequent language development closer to school entry.

Children in the current study were not all poor but their families were living in poor rural communities. Poverty rates in rural and urban areas have been increasing over the last ten years (O'Hare, 2009), with rural children living in families with higher poverty rates than children in urban areas. These higher poverty rates are reflected in lower paying jobs, lower funding for schools, less access to health and educational resources, and in the lower readiness skills of the rural children as they enter school (Lee \& Burkam, 2002). Another contributing factor to lower readiness skills may be that families in poor rural communities have access to predominately lower-quality center-based care (Gordon \& Chase-Lansdale, 2001), and while the teachers and child care providers in rural areas have more experience, they receive lower pay and have less education than urban teachers (Provasnik et al., 2007). 
Further, no matter what kind of child care families choose, rural families have to travel farther for child care and for work because of geographic isolation, resulting in reduced time for family life (O'Hare, 2009). Overall reduced access to resources, higher poverty rates, and poorer jobs for parents place children living in poor, rural communities at even greater risk for lower levels of school readiness compared to other children. Thus, it seems particularly important to examine the key contexts for children's early development, including the overall quality of care in the home and child care setting, and also to identify possible buffers that can enable at-risk, rural children to gain needed readiness skills as they enter school. We are especially interested in understanding the language environment of the home and of the child care setting as key contextual influences on the development of the children in this rural setting.

\section{Maternal Language Input and Children's Language Development}

In this paper, we examined two aspects of language in the home environment through maternal language input during a wordless picture book task: language diversity and language complexity. Language diversity included measures of the number of different words that were used and the kind of different words used that might foster interaction during the shared book task. Language complexity included the grammatical complexity of maternal language, including her mean length of utterance (MLU) in morphemes (smallest meaning unit in the language) which was used as one indicator of complexity. In addition, markers of grammatical complexity like complex conjunctions (because, before, after, although, while, until) have been used because they reflect cognitively complex constructs like causality, temporal order, duration and simultaneity (Feagans, 1980a, 1980b) and have been found to be acquired later in childhood by normally developing children.

Maternal diversity of vocabulary has generally been found to be predictive of children's current as well as later language, especially in samples of low-income children (Hart and Risley, 1995; Pan, Rowe, Singer and Snow; 2005; Rowe, 2012). For instance, Hart and Risley (1995) found that the vocabulary of less-educated mothers during the preschool years was much less diverse than the vocabulary of more-educated mothers and that this difference in vocabulary became greater over early childhood and was related to children's later language and academic skills.

Although maternal vocabulary has consistently been related to children's vocabulary and language, some studies have identified maternal complexity of language as another important aspect maternal language. Hoff and Naigles (2002) argued that maternal sensitivity and responsiveness may be critical for the acquisition of beginning language in infancy. However, they argued that after children have acquired some basic language vocabulary and syntax, the diversity and complexity of maternal language input may become more important for children's language development. They hypothesized that the use of language, not just displaying sensitive or warm parenting, was important because both maternal diverse vocabulary and syntactic complexity can provide the vocabulary variety and cognitive complexity children need to acquire more sophisticated aspects of language. Hoff and Naigles (2002) examined whether the overall quantity of sensitive and responsive conversations between mothers and children during toddlerhood was predictive of child vocabulary, or whether more specific features of maternal language input, such as vocabulary diversity and syntactic complexity, were more important in predicting child vocabulary in toddlerhood. They found that the variation in the extent to which mothers and children were engaged in sensitive and responsive conversations had little influence on child diversity of vocabulary. In contrast, variation in the lexical richness and syntactic complexity of maternal language input during mother-child interactions did account for variation among children's language vocabulary. A number of studies have supported the hypothesis that maternal complexity of utterances as well as maternal diversity of 
vocabulary may be related to children's early language. Hoff (2003) found that collegeeducated mothers produced longer utterances that were related to child growth in vocabulary over time during toddlerhood. In related studies (Bornstein, Haynes, \& Painter, 1998; Hoff $\&$ Tian, 2005), maternal MLU was a positive predictor of early child vocabulary.

\section{Maternal-Child Book Sharing and Child Language Development}

One context that has often been used to measure maternal language diversity and complexity as well as child language has been the shared book situation (Ninio \& Bruner, 1978). The language scaffolding that mothers use in this situation has been linked to children's later language and literacy skills (Payne, Whitehurst, \& Angell, 1994; Sénéchal, 2006). Researchers have demonstrated that maternal book reading interactions enhance children's vocabularies and other foundational skills in literacy (Bus, van Ijzendoorn \& Pellegrini, 1995; Dickinson, De Temple, Hirschler, \& Smith, 1992; Ninio, 1983; Sénéchal, 2006; Sénéchal \& LeFevre, 2002; Sénéchal, LeFevre, Hudson, \& Lawson, 1996; Snow \& Ninio, 1986: van Kleeck, Stahl, \& Bauer, 2003). According to Sénéchal, Pagan, Lever, and Oullette (2008), shared reading between a parent and child can promote language and literacy development in a number of ways. Shared reading allows parents to introduce complex language to the child, as compared to the oral language used during more typical parentchild interactions. It also provides an optimal context for the parent to ask questions about the book and provide expansions about what the child has said, and it can be a natural context in which to define words that are new to the child (Sénéchal \& Le Fevre, 2002). Results from the Sénéchal studies showed that children's exposure to books was related to the development of vocabulary and listening comprehension skills that were later linked to reading achievement. In a recent experimental study, book reading was causally related to children's later vocabulary and reading (Lever \& Sénéchal, 2010).

Together, these studies have identified both the kind of language parents use to promote children's language and the contexts that might be most important for that input. Maternal vocabulary diversity and maternal complexity of language were identified as the aspects of maternal language input that might be most important in predicting children's language and emergent literacy and the shared book situation may be an important context to measure how parental language is linked to child language.

\section{Caregiver-Child Verbal Interactions and Children's Language Development}

While contributions of specific maternal language inputs in the home are known to benefit children's language development, understanding the role of language inputs in the child care setting remains less clear, which is particularly true in studies that have also examined the child's home environment. The NICHD ECCRN studies $(2000,2003,2005)$ suggested that the early predictors of children's language at 36 months of age were highly related to the quality of the home environment, including observed maternal stimulation in the home, but only modestly related to stimulation in the child care setting (NICHD ECCRN, 2000). There was no evidence in these studies that children from low-income homes benefited more from the language stimulation in the child care setting than other children.

On the other hand, descriptive and experimental studies of child care and/or preschool interventions have shown that teacher quality and/or teacher language practices in the classroom can make a difference for children's language and emergent literacy skills, although, notably, these studies did not examine language in the home setting. Some recent intervention studies have found that child care and preschool teachers who were taught specific language-enhancing strategies increased the children's language and literacy skills (Cabell et al., 2011; Girolametto \& Weitzman, 2002; Girolametto, Weitzman, \& Greenberg, 2003; Justice, Mashburn, Pence, \& Wiggins, 2008; Landry, Anthony, Swank, \& Monseque- 
Bailey, 2009; Landry, Swank, Smith, Assel \& Gunnewig, 2006; Vernon-Feagans, Hurley, Yont, Wamboldt, \& Kolak; 2007, Wasik, Bond \& Hindman, 2006; Wasik \& Hindman, 2011). Landry and colleagues (Landry et al., 2006, 2009) reported that preschool teachers who had a language coach who aided the teacher implement a comprehensive languagebased curriculum helped children's language comprehension, vocabulary, and emergent literacy skills. In a more targeted program that taught teachers specific language stimulation practices (Justice et al., 2008), a randomized controlled trial found that children's language could be improved in preschool if teachers used language-stimulation strategies such as open-ended questions and recasts, but only when child attendance was high over the year. In a recent randomized controlled trial, Wasik and colleagues (Wasik, et al., 2006; Wasik \& Hindman, 2011) used literacy coaches to train Head Start preschool teachers on how to extend ideas and vocabulary from interactive book reading activities. Findings suggested that children who received this program in Head Start dramatically improved their vocabulary skills; furthermore, the children who came into Head Start with the lowest vocabulary skills gained the most from the language intervention.

While these previous studies examined the language use by teachers and children in the child care setting, they did not gather similar language measures between mother and child in the home setting, except to control for overall home quality. Thus, the extent to which specific language interactions in child care contributed unique variance in predicting child language above and beyond the contribution of the home environment was not fully explored.

\section{The Buffering Effect of High-Quality Child Care}

Although the direct effects of language experiences at home and child care are important in understanding children's development, it is also important to understand if caregiver-child language interactions might buffer children against poorer language when they receive less language input from their mothers at home. Although no previous studies have specifically looked at caregiver-child verbal interactions as a buffer for children who receive less language input in the home, some recent work has examined how high-quality child care experiences might be more important for children who come from families with fewer educational and home resources. The recent studies mentioned earlier in this review have found that children from lower-resourced home environments may be buffered against poorer cognitive, language, and social outcomes by the provision of high-quality child care (Burchinal et al., 2000; Dearing et al., 2009; Magnuson, Meyers, Ruhm, \& Waldfogel, 2004; McCartney et al., 2007; NICHD ECCRN, 2000). Using a large dataset of three child care samples, Burchinal and colleagues (2000) found some evidence for the buffering effect of high-quality care, especially for low-income African American children's language development. In a later study, child care quality buffered African American children from the negative effects of social risk on later math performance and problem behaviors in elementary school (Burchinal, Roberts, Zeisel, Hennon, \& Hooper, 2006). In a study of 11 state prekindergarten programs, Magnuson et al. (2004) found similar buffering for children from high-risk backgrounds (low maternal education, single parenthood) in predicting school readiness skills.

A particularly important article relevant to the current study was a child care study conducted by McCartney (1984). The results of this study suggested that although the overall quality of child care was important in predicting the language development of preschool children, the most salient feature of quality that related to children's language was the teacher's initiations of language to the target child and the child's verbal initiations to the teacher, as well as the child's verbal responding to the teacher. Evidence suggested an interaction between child skill and caregiver-child language interactions, such that children with lower language skills benefited more from caregiver-child verbal interactions than 
children with higher language skills. These studies were important in understanding how high-quality care, and especially child care verbal interactions, might buffer children who were at risk because of poverty, but these studies did not have relevant information on the language mothers used in the home setting.

In summary, the studies to date find that maternal language predicts child language, teacher support and interactions predict child language, and that overall child care quality might be more important for low-income/at risk children than other children in predicting school readiness. The purpose of the current study was to understand if maternal language, measured as the diversity and complexity of mother's language during a picture book session with their child in the home at three years of age, as well as positive caregiver-child verbal interactions at three years of age in the child care setting, might contribute to children's concurrent and later language development. Like Hoff and Naigles (2002), we hypothesized that these specific language input strategies by parents and specific language interactions with caregivers would be more important in predicting early language development than the overall quality of parenting or the overall quality of child care in predicting children's language development. Unlike most previous studies, we controlled for a host of socioeconomic (SES) variables, child skill variables, and child care structural characteristics. Unique to this study was the stringent use of controls for the overall quality of the home and child care settings so that we could examine whether the language-specific interactions in the home and child care setting might add additional unique variance in the prediction of concurrent and later child language. Thus, we hypothesized that caregiverchild verbal interactions in the child care setting would buffer children against poorer language skills, both concurrently and later, when the children received less maternal language input in the home, even after SES, child skills, child care characteristics, and the overall quality of the home and child care are taken into account.

\section{Method}

\section{Design and Sample}

The data were drawn from the Family Life Project, a longitudinal project designed to study families who live in two rural geographic areas with high child poverty rates east of the Mississippi (Dill, 1999). Our definition of rural at the county level included Beale Codes 3, 4 and 6, where rural was synonymous with counties that contained mid-size and small towns somewhat distant from urban centers (Butler \& Beale, 1994). We only included counties where there was no town with a population of greater than 50,000 and we excluded counties that were adjacent to large metropolitan areas so that our target counties could not be considered suburban. The study was comprised of a representative sample of every baby born to a mother who resided in one of six rural poor counties in North Carolina and Pennsylvania over a one-year period. Recruiters visited hospitals in counties every day for one year and also searched birth records for mothers who lived within the target counties but delivered their babies elsewhere. Households that did not speak English as their primary language in the home were excluded from consideration. African American families and families in poverty were oversampled to ensure adequate power for dynamic and longitudinal analyses of these families. All 1,292 families were formally enrolled in the study after the completion of a home visit when the target child was 2 months of age. The contact rate for mothers in the hospital was over $90 \%$ and the acceptance rate for eligible families was $82 \%$ (see Vernon-Feagans et al., 2008 for more details of the sampling design and recruitment process). Over $96 \%$ of the primary caregivers in the project were biological mothers. Other primary caregivers could be grandmothers, fathers, and foster mothers. However, as almost all primary caregivers were mothers, we will refer to these primary caregivers as mothers in this paper. To ascertain reading levels, all primary and secondary 
caregivers completed the KFAST literacy screener (Kaufman \& Kaufman, 1994) during their first visit. Participants who read at an eighth grade reading level or above were given the opportunity to complete questionnaires on their own ( $86 \%$ of the sample), whereas those who read below an eighth grade reading level had questionnaires read to them by one of the home visitors.

\section{Participants}

For both 36-month and pre-K outcomes, we use a reduced sample of 433 children for whom child care data were collected at 36 months (i.e., they were in some form of child care for at least 10 hours per week, and their caregiver-child language interactions were rated during the child care visit). Because a large number of children were not in child care at 36 months ( $n=778$, or $60.22 \%$ of the full sample), we did not include them in this paper. In a comparison of the demographic variables of the final subsample to those who were not in child care at 36 months, $t$-tests showed that the current subsample in child care had slightly higher socioeconomic resources. For example, those who were not in child care had lower income-to-needs ratios $(M=1.74, S D=1.62, t(1121)=-3.30, p=0.001)$, mothers with lower education levels $(M=12.79, S D=2.01, t(1121)=-3.79, p<0.001)$, and more children in the home $(M=2.46, S D=1.18, t(1121)=1.03, p=0.005)$. With few exceptions, these differences held true for children at 48 months of age as well.

Descriptive statistics of the child care subsample at 36 and 48 months are presented in Table 1. At 36 months, the average income-to-needs ratio for the households was 2.06 , with a range of 0 to 7.94 (see the discussion of control variables, below, for definition and calculation of this variable). The mother's mean age was 29.21 and the mean number of years of education was 13.25 (i.e., some education beyond high school). Just over half of the children were African American (52.19\%), and the remaining children were white (47.34\%), American Indian $(0.23 \%)$, or Asian $(0.23 \%)$. The mean number of hours per week target children were in child care was 35.66 hours and $58.20 \%$ of children attended formal, centerbased child care. These numbers and percentages were similar at 48 months, except that families had a reduced income-to-needs ratio of 1.80, with a range of 0 to 8.22. In addition, children at 48 months were only in their primary child care arrangement an average of 28.04 hours per week and $93.35 \%$ were in formal, center-based care.

\section{Procedure}

Home and child care visits took place across the child's first five years of life, but data for this paper came from the 36- and 48-month home visit as well as the 36-month child care and pre-K child care (spring before kindergarten) visit. Family and child demographic information were pulled from 36- and 48-month home visits. Two home visitors visited the families at each time point in order to collect the data in a timely fashion and to ensure that all tasks were completed successfully. The majority of FLP home visitors resided in the counties in which the families lived and in North Carolina, African American home visitors were selected to make sure all home visits to African American families included a home visitor of the same race. Almost all home visitors remained with the study across all time points, which was a major factor in the study's low attrition rate of $2 \%$ at age 3 and less than $10 \%$ at school age. Home visitors conducted interviews with the child's primary caregiver, administered questionnaires, and rated the quality of the home environment. At the 36month visit, home visitors videotaped mother-child language interactions during a wordless picture book task. Child care information was collected by two home visitors at the 36month child care visit, when interviews were conducted with the caregiver, the caregiver filled out questionnaires, and observations of the child care setting were gathered (note that a 48-month child care visit was not conducted). In addition, information was collected by one home visitor during a pre-K child care visit (the spring before children entered 
kindergarten), during which teachers completed online questionnaires and an online interview, and observations of the pre-K child care setting were gathered. Child assessments were conducted wherever the child was in a preschool or child care program or at home in the spring before they started kindergarten.

\section{Measures}

Maternal language input-Maternal language was measured during a wordless picture book task at the 36-month home visit. For this task, FLP adapted wordless picture books from standard picture books. These books were piloted for acceptability and interest by a wide range of parents from different economic levels and ethnicity. Pictures in the books were altered to make sure the characters were ambiguous with respect to ethnicity. The picture book task included two books from the Frog series by Mercer Mayer, Frog Where Are You? (Mayer, 1969) and A Boy, A Dog, A Frog, and A Friend (Mayer, 1971). Two books were used because both the mother (primary caregiver) and the father (secondary caregiver) were asked to look at the book with their child. The books were counterbalanced across families so that half the mothers were asked to read each of the books. Because of the limited number of secondary caregivers in FLP, only the mother data were used in this paper. The mother was first given the picture book so she could look through it and ask any questions she had about the task. There were seven questions scattered throughout the book to help stimulate conversation and to help the child understand the storyline. (These questions were carefully read to the parent and procedures were used to support parents whose reading levels were below the eighth grade, as described earlier.) The mother was told to help the child answer these questions so the child would get the essence of the story. Although these questions added variation to the more traditional picture book task protocol, this addition helped to promote mother-child talk that was relevant to the story. After the introduction to the book, the mother was then told to go through the book with the child and to let the home visitors know when she was finished. The time of the picture book session varied, but the home visitors were told to end the session after ten minutes if the mother had not signaled that she was finished by that point.

The picture-book sessions between the mother and the child were transcribed using the Systematic Analysis of Language Transcripts software (SALT; Miller \& Chapman, 1985). Transcribers were trained by a senior research assistant who spent one year learning SALT conventions and developing a training manual. Transcribers used the training manual to learn the specific conventions of SALT and transcribed 20 mother-child sessions that were reviewed by the senior research assistant to ensure accuracy. Training lasted at least three months as transcribers learned the conventions and definitions of codes during transcription. As an ongoing check and for training reliability purposes, transcripts were regularly reviewed by a senior transcriber and discussed at weekly research group meetings to ensure consistency in transcription. This included not only word level accuracy but utterance boundaries and turn length as specified in the SALT manual. Finally, SALT software was used to find any further errors or omissions in the transcripts. Each SALT transcript yielded numerous language variables, which the SALT software was designed to automatically calculate. Our analysis focused on two maternal language constructs when the children were 36 months old and that have been shown to be related to children's later language: maternal language diversity and maternal language complexity.

Maternal language diversity-The following three variables were chosen for maternal language diversity: 1) the number of different word roots, 2) the total number of question words, and 3) the total time in seconds that mothers spent with the book. For statistical reasons, maternal language diversity needed to include a combination of three relatively uncorrelated variables that represented this construct. For instance, total number of words 
could not be used because it correlated 0.91 with number of different words. The number of different word roots represented the mother's diversity of vocabulary during the task. This was determined on the basis of unique free morphemes (word roots) across the entire picture book session. Repetitions and variations in the words were not counted as separate root words. For instance, 'talk' and 'talked' would be considered the same root word. Omitted and unintelligible words were not included. The total number of question words was a count of the number of those words that suggested a question was being asked. These included such words as "who," "what," "where," "when," "how," and "why" words. The total time was defined as the number of seconds each mother interacted with her child during the picture-book task. Timing commenced when the mother had been given the book and the instructions for the task had been delivered. The end of the task was the time point when the mother signaled the home visitor that the activity was completed, or when 10 minutes had elapsed. Mother time with the book varied considerably and was not highly correlated with the number of different words since some mothers lingered over pictures without saying anything or using communicative non-verbal language not captured by the actual language measures. At 36 months, raw means and standard deviations of these variables for the subsample were as follows: the number of different root words per book interaction was 114.36 (38.59), the total number of question words was 29.30 (16.57), and the total time in seconds was 312.21 (125.98). The internal consistency estimate (Cronbach's a) for the current sample on these three variables was 0.85 . To create the composite of maternal language diversity used in regression analyses, the variables were standardized with a mean of 0 and standard deviation of 1 and then averaged.

Maternal language complexity-Similarly, three maternal language variables reflected maternal language complexity, including: 1) mean length of utterance, 2) the number of complex conjunctions and 3) mean turn length. Mean length of utterance (MLU) in morphemes was a general measure of the complexity of language used by the mothers and was calculated by dividing the total number of morphemes by the total number of utterances. The number of complex conjunctions was the number of complex words that generally signaled some form of embedding of clauses. They included such words as "before," "after," "while," "since," "until" "although," and "because," but did not include simple conjunctions like "and" or "but." In order to verify that these words were actually used as conjunctions, thirty randomly-selected transcripts were coded for the use of these words to verify their use as conjunctions (rather than prepositions). Across the transcripts, these words were used as conjunctions 79 times (an average of 2.63 per transcript) while they were used as prepositions 9 times (an average of 0.30 per transcript). Based on this examination of randomly selected transcripts, it appears that the mothers generally used these complex words as conjunctions rather than as prepositions. The mean turn length was the average number of words that the mother used in each conversational turn, suggesting that longer turns reflected more complexity of talk. The turn was terminated when someone else spoke or when there was a pause of more than 5 seconds. At 36 months, means and standard deviations of these variables were as follows: the mean length of utterance in morphemes was $4.06(0.74)$, the total number of complex conjunctions was 13.78 (14.68), and the mean turn length in words was 12.48 (17.72). The internal consistency estimate was 0.67 . The composite of maternal language complexity was comprised by standardizing and averaging the three variables.

Caregiver-child verbal interactions in child care-Caregiver-child verbal interactions were assessed using the Child Care Observational Coding System (CVI). The CVI is a time sampling, observational coding system that was initially developed for a child care study (Vernon-Feagans, Manlove \& Volling, 1996) and which was later revised (Vernon-Feagans \& Manlove, 2005). This system was based on the previous work of 
McCartney (1984), which suggested that caregiver verbal initiations and child verbal initiations to teachers were important in understanding children's later language development. The coding system provides data on the kind of initiating behavior from the child to the caregiver and peers and from the caregiver to the target child. In the current paper, we used two types of initiations: positive target child verbal initiations to the caregiver (Cronbach's $a=0.84$ ) and positive caregiver verbal initiations to the target child (Cronbach's $\alpha=0.80$ ). Verbal initiations were measured as any audible vocalization directed to a caregiver or child. Positive interactions were classified as those that were either neutral or positive nonverbally or verbally. Negativity included negative verbal tone or nonverbal gesture such as name calling, crying, or whining. Negativity of vocalizations was determined either by what was said or by how it was said. Thus, positive verbal interactions included talking that was considered to be positive. The observations were live-coded using a laptop computer. Two observations were conducted at the 36-month child care visit, with each observation lasting 10 minutes. Coders used continuous coding to identify which behaviors occurred in each 10-second block. The categories were coded one time per 10second segment if they occurred, regardless of the number of times they occurred in a 10second segment. For this study, a composite variable was created called caregiver-child verbal interactions. This composite variable was formed by summing the proportion of positive caregiver verbal initiations to the child and the proportion of child positive verbal initiations to the caregiver during the 36-month child care visit. Inter-rater reliability was obtained on $15 \%$ of the observations collected at 36 months of age, with an average Cohen's kappa of .79.

Child language development-Two subtests from standardized tests were used to measure the target child's expressive language development at 36 months and receptive language at a pre-K visit. These included the Preschool Language Scale, $4^{\text {th }}$ Edition (PLS-4; Zimmerman, Steiner, \& Pond, 2002) at 36 months and the Peabody Picture Vocabulary Test, $4^{\text {th }}$ Edition (PPVT-4; Dunn \& Dunn, 2007) at the pre-K visit.

The PLS-4, a norm-based measure of children's language skills from birth to age 6, was used to measure expressive language at 36 months. The PLS-4 yields two subscale measures: Auditory Comprehension and Expressive Communication. Only the Expressive Communication Subscale of this test was administered. This subscale measured how well the child communicated with others. Infant and toddler tasks initially assessed rudimentary aspects of expressive language, such as the ability to make sounds of pleasure, and later involved tasks that required the child to demonstrate verbally an understanding of language concepts, such as plural tense. For Expressive Language, test-retest reliability for this age group was reported as .82, and internal consistency estimates were .91 (Zimmerman et al., 2002). At 36 months, the average PLS score was 99.30.

The PPVT-4 was administered to provide a norm-referenced index of children's single-word receptive vocabulary knowledge. Receptive vocabulary has been established as an important indicator of children's cognitive and linguistic development, especially in its potential to help aid children's reading ability and comprehension (Dunn \& Dunn, 2007). The child's task was to select the picture considered to best illustrate the meaning of a stimulus word presented orally by the examiner out of pictured arrays of four possible answers. By assessing children's comprehension of spoken Standard American English, this tool helped to determine the vocabulary acquisition of the target children. Test-retest reliability for the PPVT-4 was .93, and internal consistency estimates averaged between .92 and .97 (Dunn \& Dunn, 2007). At the pre-K visit, the average PPVT-4 score for the subsample was 93.18.

Control variables-Family, child, and child care variables were used as controls if previous literature had shown they were related to child language (Vernon-Feagans, Cox \& 
the Family Life Project Key Investigators, in press). Family-level control variables included a host of demographic variables as well as a variable that measured the quality of the home environment. Consistent with Hanson, McLanahan, and Thomson (1997), household income was based not only on those people related by blood, marriage, or adoption, but also on anyone who resided in the household. Individuals were considered to be residing in the household if they spent three or more nights there per week. The total annual household income for the family was divided by the federal poverty threshold for a family of that size and composition to create the income-to-needs ratio, which was calculated using the 2006 poverty threshold values. Other family and community control variables included: region/ location (state of residence), maternal education in years, maternal age, marital status, and the number of children under 18 in the household. The overall quality of the home environment for the child was measured by the HOME (Bradley, 1994; Bradley, Caldwell, \& Rock, 1988). Home visitors were initially trained by Bob Bradley on the correct administration of the HOME in order to measure the quality and quantity of stimulation and support available to each child in the home environment. The Family Life Project used three HOME subscales at 36 months: 1) Responsivity, 2) Acceptance of the child, and 3) Learning materials. Each of these 22 items (e.g., "Caregiver's voice conveys positive feelings toward the child") was scored by trained research assistants in a yes/no fashion, with scores ranging from 0 to 22. The 36-month total HOME score used in these analyses was created as the proportion of items scored as yes, or 1 (Pungello et al., 2010). The 36-month HOME was used for both the 36 month and pre-K outcomes; the internal consistency estimate for the current sample was 0.78 .

Child-level controls included child's age, gender, race, negative temperament, mental development index, and a maternal composite rating of the child's language/speech skills. Child temperament was measured from the Observation of Child Temperament Scale (OCTS; Stifter, Putnam, \& Jahromi, 2008), which was collected at 36 and 48 months. The OCTS was adapted from the Infant Behavior Record (IBR; Bayley, 1969) and completed individually by two home visitors whose ratings were averaged. Two items, responsiveness to novel persons (reverse-coded) and shyness/fearfulness, were standardized with a mean of 1 and averaged to create a negative temperament composite; the internal consistency estimate at 36 months was 0.83 and 0.80 at 48 months. Negative temperament was used as a control variable because our previous work suggested that negative temperament predicted maternal the language input variables used in this study (Vernon-Feagans et al., 2008). Child mental development index (MDI) was assessed using the Bayley Scales of Infant Development-II at 15 months (Bayley, 1993). The MDI is a standard series of developmental tasks that measures children's cognitive development and was used to predict to both the 36 month and pre-K outcomes; for the current sample, internal consistency was 0.80 . Further, in order to account for children's earlier language skills, the Infant-Toddler Checklist from the Communication and Symbolic Behavior Scales Developmental Profile (CSBS; Wetherby \& Prizant, 2002) was used. Mothers completed CSBS in seven areas: Emotion and Eye Gaze, Communication, Gestures, Sounds, Words, Understanding, and Object Use. Results were summarized by adding raw scores for each area and creating three composite scores: social, speech, and symbolic communication. Because we were interested in children's language, we used the language/speech composite for these analyses, which had an internal consistency estimate of 0.68 for the current sample.

Child care control variables included the number of hours in child care per week, which was reported by the target child's child care caregiver at 36 months for the PLS-4 outcome and by the target child's prekindergarten teacher for the PPVT-4 outcome. Another variable to account for amount of care was the number of time points target children were in child care. At $6,15,24$, and 36 months as well as pre-K, children scored 1 on a dummy variable if their caregiver or teacher reported caring for them. These scores were then summed, with the 
possibility of 1-4 time points at 36 months and $2-5$ time points at pre-K. Caregiver at 36 months and prekindergarten teacher report of child care type was included as an additional child care control variable. This was dummy coded as 0 for formal care (if the care took place in a center-based environment) and 1 for informal care (if the care took place in a home environment). Due to the low percentage of children in family child care homes (3.5\% at 36 months and no children at pre-K), this type of care was categorized as informal care.

Like home environment quality, child care quality at 36 months was measured using the HOME (Bradley, 1994; Caldwell \& Bradley, 1984). Research assistants spent about one and a half hours in the child care setting and filled out the HOME, which had an internal consistency estimate of 0.62 for the current sample. Pre-K classroom quality was measured by using the Instructional Support scale from the Classroom Assessment Scoring System (CLASS), which is an observational system for assessing classroom quality in preschool through elementary school (La Paro, Pianta, Stuhlman, 2004; Pianta, La Paro, \& Hamre, 2008). All observers attended a three-day training workshop led by certified CLASS trainers from the University of Virginia. In order to be certified as a CLASS observer, all observers had to attend the training, practice observing and coding videotapes of classrooms, and become certified coders by reaching the competence level needed to become a certified CLASS observer. The three dimensions of Instructional Support are concept development, quality of feedback, and language modeling (Pianta, et al., 2008). During these observations, trained research assistants carefully observed interactions between the teacher and the students in the classroom but not specifically the target children in the FLP project. The CLASS and its dimensions were based wholly on interactions between teachers and students in classrooms and not based on the presence of materials, the physical environment, safety, or curriculum. The CLASS is a well-validated tool that provides evidence that higher scoring classrooms have students who make greater academic and social progress, with an average inter-rater reliability is .87. The internal consistency of Instructional Support within a recent study was 78 (Pianta, et al., 2008). The internal consistency estimate for the current sample on Instructional Support was 0.84 .

\section{Results}

\section{Preliminary Analyses}

To account for missing data within the subsample (ranging from 1-15\% of covariate data and $1-8 \%$ of outcome data), multiple imputation was conducted in SAS 9.2, using PROC MI to create 30 imputed data sets. Multiple imputation serves to reduce bias due to missing data in longitudinal research designs, with researchers recommending imputation with at least 25 data sets (Spratt et al., 2010). Descriptive findings (Tables 1, 2, and 3) are presented using non-imputed data while all regression results use the imputed sample (Tables 4, 5, 6, and 7). We used Hedges' $g$ (Cooper \& Hedges, 1994) to compute effect sizes, which were calculated for both main effects and interactions. Effect sizes for the interactions were calculated at one standard deviation above and below the mean to give an estimate of the importance of the interaction effects.

\section{Data Analysis Plan}

To answer the questions related to the influence of maternal language diversity and complexity and caregiver-child interactions on children's PLS-4 Expressive Language score at 36 months and the PPVT-4 Receptive Language score at pre-K, four hierarchical regressions were reported: two at 36 months and two at pre-K. The first regression examined whether maternal language diversity and caregiver-child verbal interactions at 36 months predicted concurrent child expressive language while the second regression examined whether maternal language complexity and caregiver-child verbal interactions predicted 
concurrent child expressive language. The final two regressions were similar to the first two regressions but were predicting pre-K receptive language approximately two years later. All variables were mean-centered for regression analyses.

We used five steps in the hierarchical regression in block-wise fashion. In the first step, we entered 13 child and family characteristics as covariates (using 36-month data for the 36month regressions and 48-month data for the pre-K regressions) that have been linked to child language, including SES-related variables, child characteristics and skills, as well as the quality of the home environment. The thirteen covariates were: region/location, incometo-needs ratio, maternal education, maternal age, marital status, number of children under 18 in the household, the quality of the home environment for the child, child age, gender, race, negative temperament, and 15-month mental development index and 15 month language/ speech composite. In the second step, we added four child care characteristics as covariates (again using 36-month data for 36-month regressions and 48-month data for pre-K regressions), which included the number of hours in child care per week, number of time points in child care, type of care, and overall quality of child care. In the third step, we added maternal language input (diversity or complexity) at 36 months. In the fourth step we added caregiver-child verbal interactions at 36 months of age. Finally, in the fifth step we added interaction terms between maternal language input at 36 months and caregiver child verbal interactions at 36 months, predicting both outcomes.

\section{Correlations}

The zero-order correlations for all analysis variables are presented in Table 2 for 36-month covariates and outcome and Table 3 for 48 -month covariates and outcome. In general variables were moderately correlated with each other and in the right direction. Maternal language diversity and complexity were positively correlated with each other at .42, but are considered to represent fairly distinct aspects of maternal language.

\section{Regression Results: Expressive Language (PLS-4) at 36 months}

For both maternal language diversity and complexity, the same set of covariates for social and family context and child characteristics were significantly related to the child expressive language (see Step 1 in Tables 4 and 5). The control variables in Step 1 accounted for 38.1\% of variance in 36-month expressive language scores. In Step 2, four child care control variables were added, which accounted for approximately $1 \%$ additional variance in the model, $R^{2}=.389, F=1.37, p=.23$. Only child care quality was a significant predictor of child expressive language, but this variable became non-significant in Step 3 when maternal language diversity was added to the model.

Maternal language diversity-As seen in Step 3 of the first regression (Table 4), maternal language diversity was not significantly related to children's expressive language, $R^{2}=.391, F=0.69, p=.45$. In Step 4, caregiver-child verbal interactions $(B=3.96, p=$ 0.04 ) were positively associated with children's expressive language, $R^{2}=.397, F=4.11, p$ $=.04$, with a small effect size $(d=0.10)$. In Step 5, adding an interaction term of maternal language diversity by caregiver-child verbal interactions was not significant $\left(R^{2}=.401, F=\right.$ $2.82, p=.09$ ) but was in the same direction as the other significant interactions described below.

Maternal language complexity-As seen in Step 3 of the second regression (Table 5), maternal language complexity $(B=2.24, p=.02)$ was significantly associated with children's 36-month expressive language scores after accounting for family and child characteristics and child care control variables, $R^{2}=.398, F=5.64, p=0.02$. In Step 4, the variable caregiver-child verbal interactions $(B=4.10, p=0.03)$ was added and was 
positively associated with children's expressive language skills, $R^{2}=.404, F=4.46, p=.03$. The effect sizes were small for the main effects of maternal language complexity and caregiver-child verbal interactions, each at $d=0.10$. In Step 5, maternal language complexity interacted with caregiver-child verbal interactions, $B=-4.56, R^{2}=.414, F=$ $6.48, p=.006$. This interactive association revealed that in the presence of low maternal language complexity, children's positive verbal interactions with their caregivers at 36 months acted as a buffer for children's expressive language development. In order to graph this interaction, values were calculated at one standard deviation below, above, and at the mean of caregiver-child verbal interactions (see Figure 1). The effect size for maternal language complexity when caregiver-child verbal interactions were one standard deviation below the mean was moderate at $d=0.26$ while the effect size at one standard deviation above the mean of caregiver-child verbal interactions was $d=0.10$.

\section{Regression Results: Receptive Language (PPVT) at Pre-K}

Like the expressive language regressions, the social and family context variables and child characteristics accounted for significant variance in children's receptive language scores at prekindergarten (see Step 1 in Tables 6 and 7). The control variables in Step 1 accounted for $42.0 \%$ of variance in receptive language. In Step 2, unlike the child care control variables at 36 months, being in formal, center-based care between 6 and 36 months was associated with higher receptive language scores at pre-K but child care quality was not a significant control variable, $R^{2}=.449, F=4.53, p=.001$.

Maternal language diversity-As seen in Step 3 of the third regression (Table 6), maternal language diversity was not significantly associated with receptive language scores, $R^{2}=.452, F=1.64, p=.16$. Likewise, in Step 4, caregiver-child verbal interactions were not associated with receptive language scores, $R^{2}=.453, F=0.58, p=.35$. However, in Step 5, the interaction of maternal language diversity by caregiver-child verbal interactions was significant, $B=-4.24, R^{2}=.462, F=5.57, p=.03$. The effect size for maternal language diversity when caregiver-child verbal interactions was one standard deviation below the mean was small at $d=0.14$. The effect size at one standard deviation above the mean of caregiver-child verbal interactions was $d=0.00$. This suggested that caregiver-child verbal interactions may buffer children at pre-K from lower scores on receptive language in the presence of lower maternal language diversity in the home at 36 months (see Figure 2).

Maternal language complexity-As seen in Step 3 of the fourth and final regression (Table 7), maternal language complexity $(B=1.78, p=.04)$ was significantly associated with children's receptive language scores, $R^{2}=.455, F=4.09, p=0.04$. The association of maternal language complexity with receptive language had an effect size of $d=0.09$. In Step 4 , caregiver-child verbal interactions was not significant, $R^{2}=.456, F=0.67, p=.33$. In Step 5, the interaction between maternal language complexity and caregiver-child verbal interactions was significant, $B=-3.32, R^{2}=.462, F=5.57, p=.05$. The effect size for maternal language complexity when caregiver-child verbal interactions was one standard deviation below the mean was moderate at $d=0.19$. The effect size at one standard deviation above the mean of caregiver-child verbal interactions was $d=0.07$. This association suggests that caregiver-child verbal interactions buffered children from poorer receptive language skills at pre-K in the presence of lower levels of maternal language complexity (see Figure 3).

\section{Discussion}

The findings from this study underscore the importance of both the specific language input by mothers at home and the language by caregivers in child care in predicting children's 
current and later language. Caregiver language interactions in child care were especially important for children whose mothers provided less language in the home. For most young children in the United States, the home and child care are the major ecological settings during the preschool years. Thus, much of the previous work on this period of development has tried to capture the quality of these two settings through ratings of their quality, using measures like the HOME (Bradley, Caldwell, \& Corwyn, 2003; Bradley \& Corwyn, 2002), or by observations that try to capture the sensitivity, emotional support, and cognitive input that represent the quality of the relationships between caregiver and child (Burchinal et al., 2000, 2006; Crosnoe et al., 2010; NICHD ECCRN, 2000, 2001). The current study has suggested that the most important aspects of the quality of the home and the quality of the child care setting in early childhood that help children may be adult language stimulation.

Most studies of language development have clearly shown the importance of maternal language input in predicting to children's early language; this has been especially true of studies that have examined SES differences in maternal language input and child language (Bornstein et al., 1998; Hart \& Risley, 1995; Hoff, 2003; Hoff \& Naigles, 2002). These previous language studies have been important but have two major limitations. Most of these studies have not been able to examine whether maternal language input might have been just a marker for a higher-quality parenting environment, because the general parenting environment was not measured or used as a control variable. In addition, these studies generally did not control for a host of variables that have been related to children's language in previous studies, such as children's overall previous language/cognitive skill level, SES, number of children in the home, length of time in child care, or hours in care. In the current study, we have addressed these limitations by controlling for 17 family background variables, child variables, child care variables and, most importantly, the overall quality of the home and the child care environment. Despite the rigorous nature of these models, we still found that specific maternal language complexity of language in the home was important in predicting children's language both concurrently at 36 months and at pre-K.

Our findings not only suggested the importance of specific language input in the home but also the importance of language input in the child care setting. This finding builds on previous work that has shown that high-quality child care is related to children's language development (Burchinal et al., 2000, 2006; NICHD ECCRN, 2000, 2003), although these previous studies were not able to measure individual child-caregiver interactions. Specifically, the current study suggests that it may be positive caregiver-child verbal interactions that might be most important in understanding the influence of high quality child care (Hoff \& Naigles, 2002; McCartney, 1984; McCartney \& Berry, 2009). The observational system used in children's child care settings captured both positive verbal interactions that were initiated by the caregiver to a specific child, as well as specific child initiations to the caregiver. These kinds of language interactions have been shown to be important in understanding children's language development and especially important for children with lower language skills (McCartney, 1984; McCartney \& Berry, 2009).

Although it was important for this study to document that both specific maternal language input and specific caregiver verbal interactions were important above and beyond overall quality of the child care and home settings, the most important contribution of this study was the specification of the possible buffering mechanism of caregiver-child verbal interactions that might help children who come into child care with less language input at home, even after controlling for SES. This finding helped to fill a gap in the literature on what actual caregiver behaviors might be most implicated in helping children's early language development, especially those children most at risk. The interaction between either maternal language diversity or complexity in the home and caregiver-child positive verbal interactions in the child care setting suggested the importance of specific language processes 
as helping buffer children from poorer language outcomes, both concurrently at 36 months and just before school entry nearly two years later. In addition, moderate effect sizes up to . 26 were associated with the interactions that appeared to buffer children from poor language scores, and to actually help children perform at age-appropriate levels on standardized language measures. Note that Figures 2 and 3 suggest the presence of almost complete buffering, such that children whose mothers used lower levels of language input scored similarly to children whose mothers used higher levels of language input only when the children with low levels of maternal language input were in child care settings with high levels of caregiver-child verbal interactions. These findings held true even after controlling for most of the variables often used to predict children's early language development. The specific findings in the current study therefore help support the speculations from previous studies about the importance of language interactions in the home and child care setting, such that it might be the language in child care that matters more for children with fewer resources in the home (Bradley \& Corwyn, 2002; Bradley et al., 2003; Burchinal et al., 2006; Crosnoe et al., 2010; McCartney \& Berry, 2009; McCartney et al., 2007).

Our study has considerable policy relevance given the numbers of young children who are both in child care and come from homes where diverse and complex language input may not be a priority. Our study certainly supports the role of the language input in the home but it specifies that verbal interactions in the child care setting may be a powerful intervention for children who come from homes that have limited language input. Although most child care teacher preparation programs clearly stress the importance of talking to children in their care (Dickinson \& Tabors, 2001), this study would suggest that highlighting the importance of increased positive verbal conversations with individual children may have lasting effects on development, especially for children who may have fewer chances to participate in stimulating verbal conversations at home.

Last, it is important to place the current study in context by discussing the background of the children in the parent study. This is one of the few developmental studies that recruited and followed a representative sample of children that included diversity with respect to race and income, including both poor and non-poor children who lived in poor rural communities. Average income-to-needs ratios at three years of age and at pre-K were at or below 2.0, suggesting that the families were struggling with incomes just above the levels that would make them eligible for many poverty programs. Of the families who used child care in the Family Life Project for more than 10 hours a week, half were African American, slightly more than in the larger sample. Thus, our FLP sample has both similarities and dissimilarities to other studies in this regard. For instance, our sample is much poorer than the NICHD ECCRN (2000, 2005) sample, whose income-to-needs ratios were over 3.5. Yet, our income-to-needs ratios are higher than some Head Start studies (Mistry, Benner, Biesanz, Clark, \& Howes, 2010), which report income-to-needs ratios around 1.

There are some clear limitations of this study. First, we were not able to record and transcribe the actual language of caregivers in the child care setting. It would be important in future studies to be able to specify the exact language used in the home and in the child care setting, much like some other child care studies have done. For instance, although Dickinson and Tabors (2001) did not examine the buffering effects of child care language on children's later school readiness, they did examine in more detail the complex conversations between caregivers and children at preschool, and found that these conversations were the best predictors of children's later language and school readiness. We also only used one wordless picture book task to gather maternal language input, which may not have been representative of all home language. Furthermore, we used an expressive language measure at 36 months of age and a different receptive language measure at pre-K. Although the results generally held across these measures, it would have been useful to use the same measure across time 
points. Last, actual randomized controlled trials will be needed in the future to understand the possible causal connections between language in the home and child care and children's later language and emergent literacy. Our study is descriptive and can only suggest these possible causal connections.

\section{Acknowledgments}

Support for this research was provided by the National Institute of Child Health and Human Development (PO1HD-39667), with co-funding from the National Institute on Drug Abuse.

\section{References}

Bayley, N. Manual for the Bayley Scales of Infant Development. New York, NY: Psychological Corporation; 1969.

Bayley, N. Bayley II Scales of Infant Development. New York, NY: Psychological Corporation; 1993.

Bornstein MH, Haynes MO, Painter KM. Sources of child vocabulary competence: A multivariate model. Journal of Child Language. 1998; 25(2):367-393. [PubMed: 9770912]

Bradley, R. The HOME Inventory: Review and reflections. In: Reese, HW., editor. Advances in Child Development and Behavior. Vol. Vol. 25. San Diego, CA: Academic Press; 1994. p. 241-288.

Bradley RH, Caldwell BM, Corwyn RF. The Child Care HOME Inventories: assessing the quality of family child care homes. Early Childhood Research Quarterly. 2003; 18(3):294-309.

Bradley RH, Caldwell BM, Rock SL. Home environment and school performance: a ten-year followup of three models of environmental action. Child Development. 1988; 59(4):852-867. [PubMed: 3168624]

Bradley RH, Corwyn RF. Socioeconomic status and child development. Annual Review of Psychology. 2002; 53:371-399.

Burchinal MR, Peisner-Feinberg E, Bryant DM, Clifford R. Children's social and cognitive development and child-care quality: testing for differential associations related to poverty, gender, or ethnicity. Applied Developmental Science. 2000; 4(3):149-165.

Burchinal MR, Roberts JE, Zeisel SA, Hennon EA, Hooper S. Social risk and protective child, parenting, and child care factors in early elementary school years. Parenting. 2006; 6(1):79-113.

Burchinal M, Vandergrift N, Pianta R, Mashburn A. Threshold analysis of association between child care quality and child outcomes for low-income children in pre-Kindergarten programs. Early Childhood Research Quarterly. 2010; 25(2):166-176.

Bus AG, Van Ijzendoorn MH, Pellegrini AD. Joint book reading makes for success in learning to read: A meta-analysis on intergenerational transmission of literacy. Review of Educational Research. 1995; 65(5):1-21.

Butler, MA.; Beale, CL. Rural-urban continuum codes for metropolitan and nonmetropolitan counties, 1993. Washington, DC: U.S. Department of Agriculture; 1994. (AGES 9425).

Cabell SQ, Justice LM, Piasta SB, Curenton SM, Wiggins A, Turnbull K, Petscher Y. The impact of teacher responsivity education on preschoolers' language and literacy skills. American Journal of Speech-Language Pathology. 2011; 20(4):315-330. [PubMed: 21856968]

Caldwell, BM.; Bradley, RH. Home Observation for Measurement of the Environment. Little Rock, AK: University of Arkansas at Little Rock; 1984.

Cohen, J. Statistical power analysis for the behavioral sciences. Hillsdale, NJ: Erlbaum; 1988.

Cooper, H.; Hedges, LV., editors. The handbook of research synthesis. New York, NY: Sage; 1994.

Crosnoe R, Leventhal T, Wirth RJ, Pierce KM, Pianta R. NICHD Early Child Care Research Network (NICHD ECCRN). Family socioeconomic status and consistent environmental stimulation in early childhood. Child Development. 2010; 81(3):972-987. [PubMed: 20573117]

Dearing E, McCartney K, Taylor BA. Does higher quality early child care promote low-income children's math and reading achievement in middle childhood? Child Development. 2009; 80(5): 1329-1349. [PubMed: 19765003] 
Dickinson DK, De Temple JM, Hirschler JA, Smith MW. Book reading with preschoolers: Coconstruction of text at home and at school. Early Childhood Research Quarterly. 1992; 7(3):323346.

Dickinson, DK.; Tabors, PO., editors. Beginning literacy with language: young children learning at home and school. Baltimore, MD: Paul H. Brookes Publishing; 2001.

Dill, BT. Poverty in the rural U.S.: Implications for children, families, and communities. New York, NY: Annie E. Casey Foundation; 1999.

Downer JT, Pianta RC, Fan X, Hamre BK, Mashburn A, Justice L. Effects of web-mediated teacher professional development on the language and literacy skills of children enrolled in prekindergarten programs. National Head Start Association Dialog. 2011; 14(4):189-212. [PubMed: 23144591]

Dunn, LM.; Dunn, DM. Peabody Picture Vocabulary Test, Fourth Edition. Minneapolis, MN: Pearson Assessments; 2007.

Feagans L. Children's understanding of some temporal terms denoting order, duration, and simultaneity. Journal of Psycholinguistic Research. 1980a; 9:41-57. [PubMed: 7365706]

Feagans L. How to make sense of temporal/spatial before and after. Journal of Child Language. 1980b; 7:529-537. [PubMed: 7440675]

Girolametto L, Weitzman E. Responsiveness of child care providers in interactions with toddlers and preschoolers. Language, Speech, and Hearing Services in Schools. 2002; 33(4):268-281.

Girolametto L, Weitzman E, Greenberg J. Training day care staff to facilitate children's language. American Journal of Speech-Language Pathology. 2003; 12(3):299-311. [PubMed: 12971819]

Gordon RA, Chase-Lansdale L. Availability of child care in the United States: A description and analysis of data sources. Demography. 2001; 38(2):299-316. [PubMed: 11392914]

Hanson, T.; McLanahan, S.; Thomson, E. Economic resources, parental practices, and children's wellbeing. In: Duncan, GJ.; Brooks-Gunn, J., editors. Consequences of growing up poor. New York, NY: Sage; 1997. p. 190-238.

Hart, B.; Risley, TR. Meaningful differences in the everyday experience of young American children. Baltimore, MD: Paul H. Brookes Publishing; 1995.

Hoff E. The specificity of environmental influence: Socioeconomic status affects early vocabulary development via maternal speech. Child Development. 2003; 74(5):1368-1378. [PubMed: 14552403]

Hoff E, Naigles L. How children use input to acquire a lexicon. Child Development. 2002; 73(2):418433. [PubMed: 11949900]

Hoff E, Tian C. Socioeconomic status and cultural influences on language. Journal of Communication Disorders. 2005; 38(4):271-278. [PubMed: 15862810]

Justice LM, Mashburn A, Pence KL, Wiggins A. Experimental evaluation of a preschool language curriculum: Influence on children's expressive language skills. Journal of Speech, Language, and Hearing Research. 2008; 51(4):983-1001.

Kaufman, AS.; Kaufman, NL. Kaufman Functional Academic Skills Test (K-FAST). Circle Pines, MN: American Guidance Service; 1994.

Landry SH, Anthony JL, Swank PR, Monseque-Bailey P. Effectiveness of comprehensive professional development for teachers of at-risk preschoolers. Journal of Educational Psychology. 2009; 101(2):448-465.

Landry SH, Swank PR, Smith KE, Assel MA, Gunnewig SB. Enhancing early literacy skills for preschool children: bringing a professional development model to scale. Journal of Learning Disabilities. 2006; 39(4):306-324. [PubMed: 16895156]

La Paro KM, Pianta RC, Stuhlman M. The Classroom Assessment Scoring System: Findings from the prekindergarten year. The Elementary School Journal. 2004; 104:409-426.

Lee, V.; Burkam, D. Inequality at the starting gate: Social background differences in achievement as children begin school. Washington, DC: Economic Policy Institute; 2002.

Lever R, Sénéchal M. Discussing stories: On how a dialogic reading intervention improves kindergartners' oral narrative construction. Journal of Experimental Child Psychology. 2010; 108(1):1-24. [PubMed: 20828708] 
Magnuson KA, Meyers MK, Ruhm CJ, Waldfogel J. Inequality in preschool education and school readiness. American Educational Research Journal. 2004; 41(1):115-157.

Mayer, M. Frog where are you?. New York, NY: Penguin Putnam Press; 1969.

Mayer, M. A boy, a dog, a frog, and a friend. New York, NY: Dial Books for Young Readers; 1971.

McCartney K. Effect of quality of day care environment on children's language development. Developmental Psychology. 1984; 20(2):244-260.

McCartney, K.; Berry, D. Whether the environment matters more for children in poverty. In: McCartney, K.; Weinberg, RA.; McCartney, K.; Weinberg, RA., editors. Experience and development: A festschrift in honor of Sandra Wood Scarr. New York, NY: Psychology Press; 2009. p. 99-124.

McCartney K, Dearing E, Taylor BA, Bub KL. Quality child care supports the achievement of lowincome children: Direct and indirect pathways through caregiving and the home environment. Journal of Applied Developmental Psychology. 2007; 28:411-426. [PubMed: 19578561]

Miller, J.; Chapman, R. Systematic Analysis of Language Transcripts (SALT): User's guide. Madison, WI: University of Wisconsin Language Analysis Laboratory; 1985.

Mistry R, Benner A, Biesanz J, Clark S, Howes C. Family and social risk, and parental investments during the early childhood years as predictors of low-income children's school readiness outcomes. Early Childhood Research Quarterly. 2010; 25(4):432-440.

NICHD Early Child Care Research Network (ECCRN). The relation of child care to cognitive and language development. Child Development. 2000; 71(4):960-980. [PubMed: 11016559]

NICHD Early Child Care Research Network (ECCRN). Nonmaternal care and family factors in early development: An overview of the NICHD Study of Early Child Care. Journal of Applied Developmental Psychology. 2001; 22(5):457-492.

NICHD Early Child Care Research Network (ECCRN). Does quality of child care affect child outcomes at age 4 1/2? ? Developmental Psychology. 2003; 39(3):451-469. [PubMed: 12760515]

NICHD Early Child Care Research Network (ECCRN). Duration and timing of poverty and children's cognitive and social development from birth through third grade. Child Development. 2005; 76(4): 795-810. [PubMed: 16026497]

NICHD Early Child Care Research Network (ECCRN). Infant-mother attachment classification: Risk and protection in relation to changing maternal caregiving quality. Developmental Psychology. 2006; 42(1):38-58. [PubMed: 16420117]

Ninio A. Joint bookreading as a multiple vocabulary acquisition device. Developmental Psychology. 1983; 19:445-451.

Ninio A, Bruner J. The achievement and antecedents of labelling. Journal of Child Language. 1978; $5: 1-15$.

O'Hare, WP. The forgotten fifth: Child poverty in rural America. Durham, NH: University of New Hampshire Carsey Institute; 2009.

Pan B, Rowe ML, Singer JD, Snow CE. Maternal Correlates of Growth in Toddler Vocabulary Production in Low-Income Families. Child Development. 2005; 76(4):763-782. [PubMed: 16026495]

Payne AC, Whitehurst GJ, Angell AL. The role of home literacy environment in the development of language ability in preschool children from low-income families. Early Childhood Research Quarterly. 1994; 9(3):427-440.

Peisner-Feinberg ES, Burchinal MR, Clifford RM, Culkin ML, Howes C, Kagan SL, Yazejian N. The relation of preschool child-care quality to children's cognitive and social developmental trajectories through second grade. Child Development. 2001; 72(5):1534-1553. [PubMed: 11699686]

Pianta, R.; La Paro, K.; Hamre, B. Classroom Assessment Scoring System (CLASS) Manual, K-3. Baltimore, MD: Paul H. Brookes Publishing; 2008.

Piasta SB, Justice LM, Cabell SQ, Wiggins AK, Turnbull K, Curenton SM. Impact of professional development on preschool teachers' conversational responsivity and children's linguistic productivity and complexity. Early Childhood Research Quarterly. 2012; 27(3):387-400. 
Provasnik, S.; KewalRamani, A.; Coleman, M.; Gilbertson, L.; Herring, W.; Xie, Q. Status of education in rural America. Washington, DC: National Center for Education Statistics; 2007. (NCES 2007040).

Pungello EP, Kainz K, Burchinal M, Wasik BH, Sparling JJ, Ramey CT, Campbell FA. Early educational intervention, early cumulative risk, and the early home environment as predictors of young adult outcomes within a high-risk sample. Child Development. 2010; 81(1):410-426. [PubMed: 20331676]

Rowe ML. A longitudinal investigation of the role of quantity and quality of child-directed speech in vocabulary development. Child Development. 2012; 83(5):1762-1774. [PubMed: 22716950]

Sénéchal M. Testing the Home Literacy Model: Parent involvement in kindergarten is differentially related to grade 4 reading comprehension, fluency, spelling, and reading for pleasure. Scientific Studies of Reading. 2006; 10(1):59-87.

Sénéchal M, LeFevre J. Parental involvement in the development of children's reading skill: A fiveyear longitudinal study. Child Development. 2002; 73(2):445-460. [PubMed: 11949902]

Sénéchal M, LeFevre J, Hudson E, Lawson EP. Knowledge of storybooks as a predictor of young children's vocabulary. Journal of Educational Psychology. 1996; 88(3):520-536.

Sénéchal M, Pagan S, Lever R, Ouellette GP. Relations among the frequency of shared reading and 4year-old children's vocabulary, morphological and syntax comprehension, and narrative skills. Early Education And Development. 2008; 19(1):27-44.

Snow, CE.; Ninio, A. The contracts of literacy: What children learn from learning to read books. In: Teale, WH.; Sulzby, E., editors. Emergent literacy: Writing and reading. Norwood, NJ: Ablex; 1986. p. 116-138.

Spratt M, Carpenter J, Sterne JA, Carlin JB, Heron J, Henderson J, Tilling K. Strategies for multiple imputation in longitudinal studies. American Journal of Epidemiology. 2010; 172(4):478-487. [PubMed: 20616200]

Stifter CA, Putnam S, Jahromi L. Exuberant and inhibited toddlers: Stability of temperament and prediction to behavior problems. Development and Psychopathology. 2008; 20:401-421. [PubMed: 18423086]

Vandell DL, Belsky J, Burchinal M, Steinberg L, Vandergrift N. NICHD Early Child Care Research Network (ECCRN). Do effects of early child care extend to age 15 years? Results from the NICHD study of early child care and youth development. Child Development. 2010; 81(3):737756. [PubMed: 20573102]

van Kleeck, A.; Stahl, SA.; Bauer, EB. On reading books to children: Parents and teachers. Mahwah, NJ: Erlbaum; 2003.

Vernon-Feagans L, Cox M. the Family Life Project Key Investigators. The Family Life Project: An epidemiological and developmental study of young children living in poor rural communities. Monographs of the Society for Research in Child Development. (in press).

Vernon-Feagans L, Hurley M, Yont KM, Wamboldt PM, Kolak A. Quality of child care and otitis media: Relationship to children's language during naturalistic interactions at 18, 24, and 36 months. Journal of Applied Developmental Psychology. 2007; 28:115-133.

Vernon-Feagans L, Manlove E. Otitis media, the quality of child care, and the social/communicative behavior of toddlers: a replication and extension. Early Childhood Research Quarterly. 2005; 20(3):306-328.

Vernon-Feagans L, Manlove EE, Volling BL. Otitis media and the social behavior of daycare attending children. Child Development. 1996; 67:1528-1539. [PubMed: 8890498]

Vernon-Feagans L, Pancsofar N, Willoughby M, Odom E, Quade A, Cox M. Predictors of maternal language to infants during a picture book task in the home: Family SES, child characteristics and the parenting environment. Journal of Applied Developmental Psychology. 2008; 29(3):213-226. [PubMed: 18618023]

Wasik BA, Bond MA, Hindman A. The effects of a language and literacy intervention on Head Start children and teachers. Journal of Educational Psychology. 2006; 98(1):63-74.

Wasik BA, Hindman AH. Improving vocabulary and pre-literacy skills of at-risk preschoolers through teacher professional development. Journal of Educational Psychology. 2011; 103(2):455-469. 
Wetherby, AM.; Prizant, BM. Communication and Symbolic Behavior Scales: Developmental profile. Baltimore, MD: Paul H. Brookes Publishing; 2002.

Zimmerman, IL.; Steiner, VG.; Pond, RE. Preschool Language Scale, Fourth Edition (PLS-4). San Antonio, TX: Psychological Corporation; 2002. 


\section{Research Highlights}

- Examined the language by mother in a picturebook task with her child in the home

- Examined caregiver-child language in the child care setting.

- Caregiver-child language interactions buffered children against poor language when mothers used lower levels of langauge 


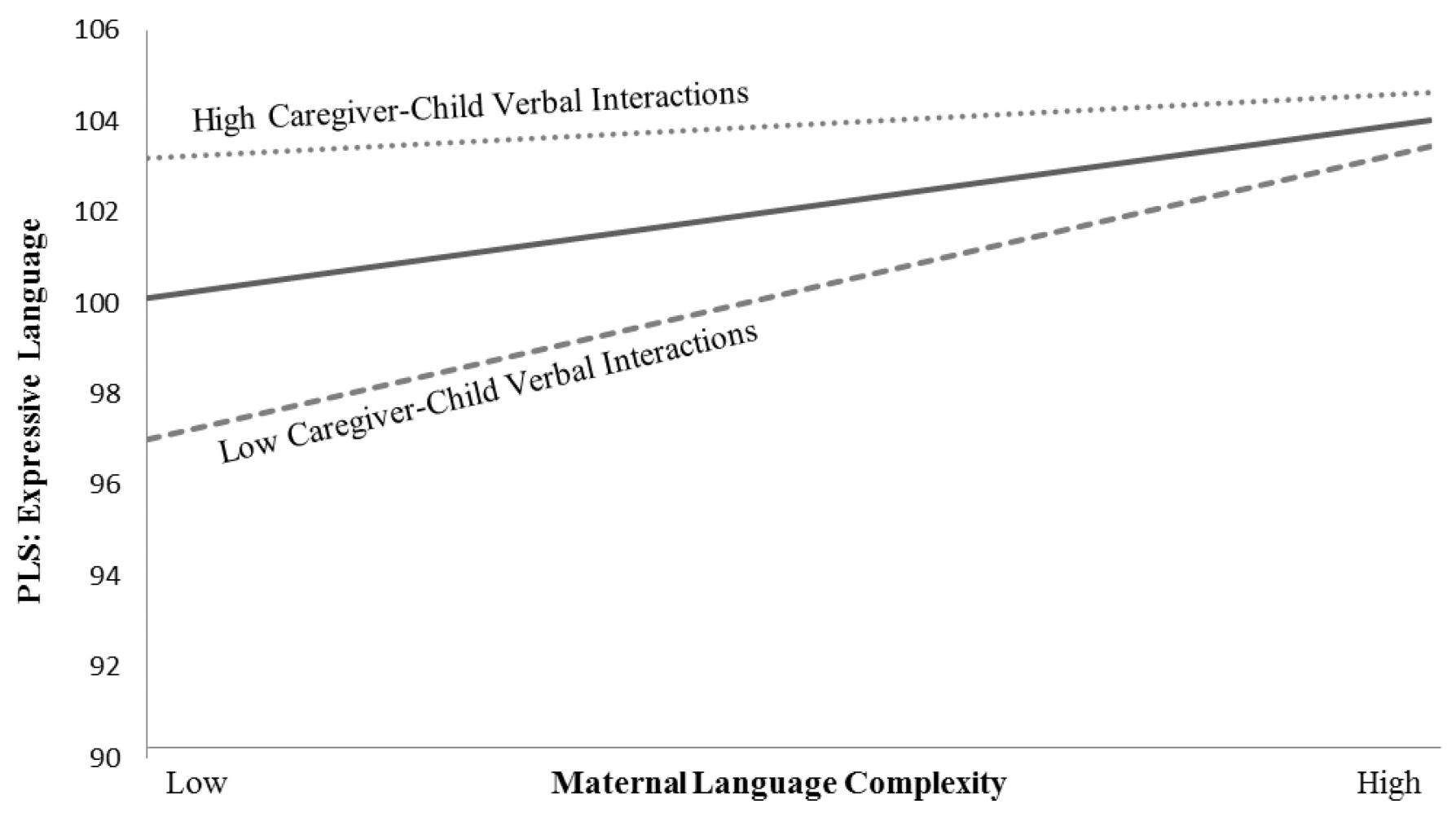

Figure 1.

Predicting Expressive Language at 36 Months: Maternal Language Complexity $\times$ CaregiverChild Positive Verbal Interactions 


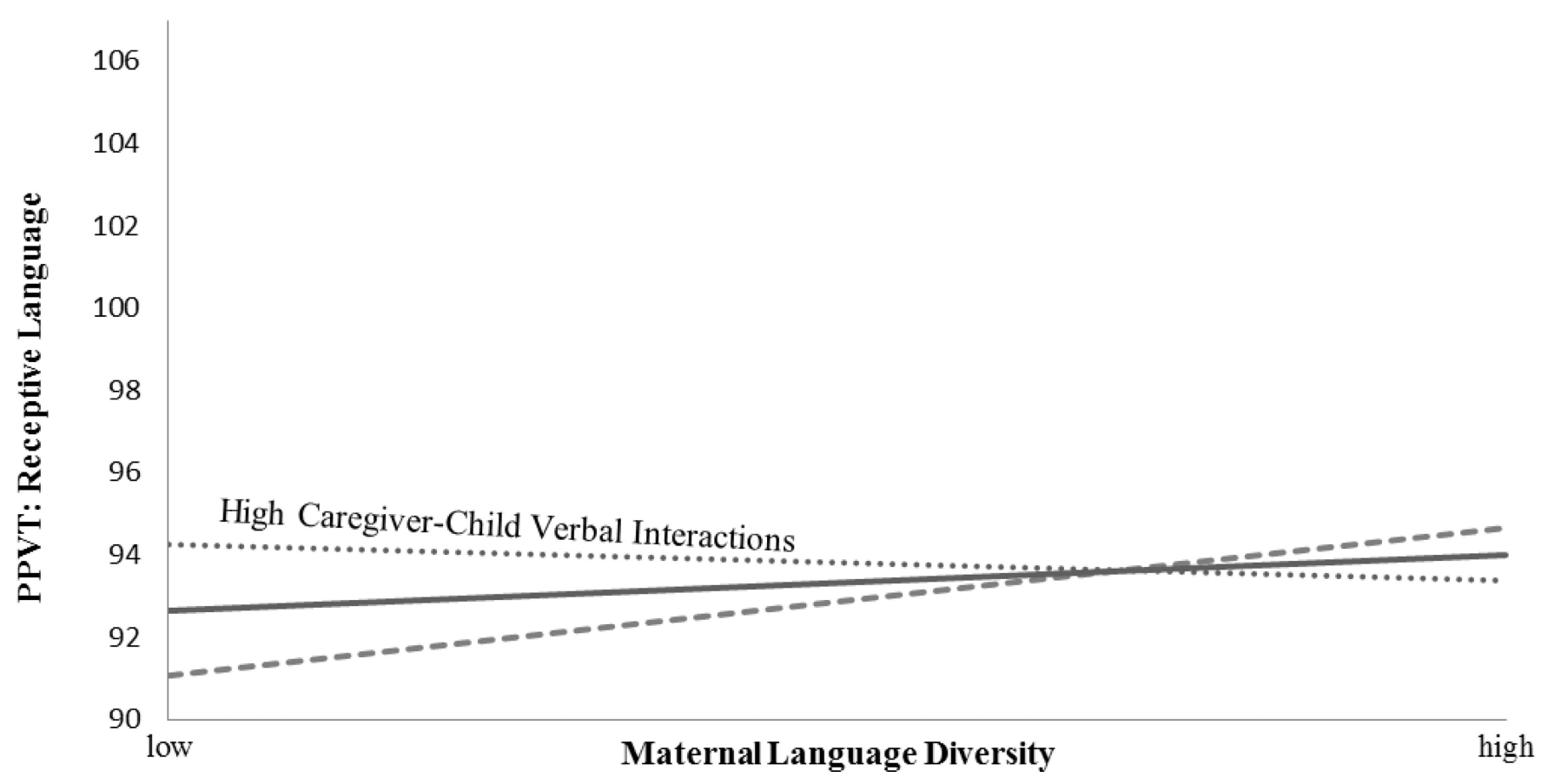

Figure 2.

Predicting Receptive Language at PreK: Maternal Language Diversity $\times$ Caregiver-Child Positive Verbal Interactions 


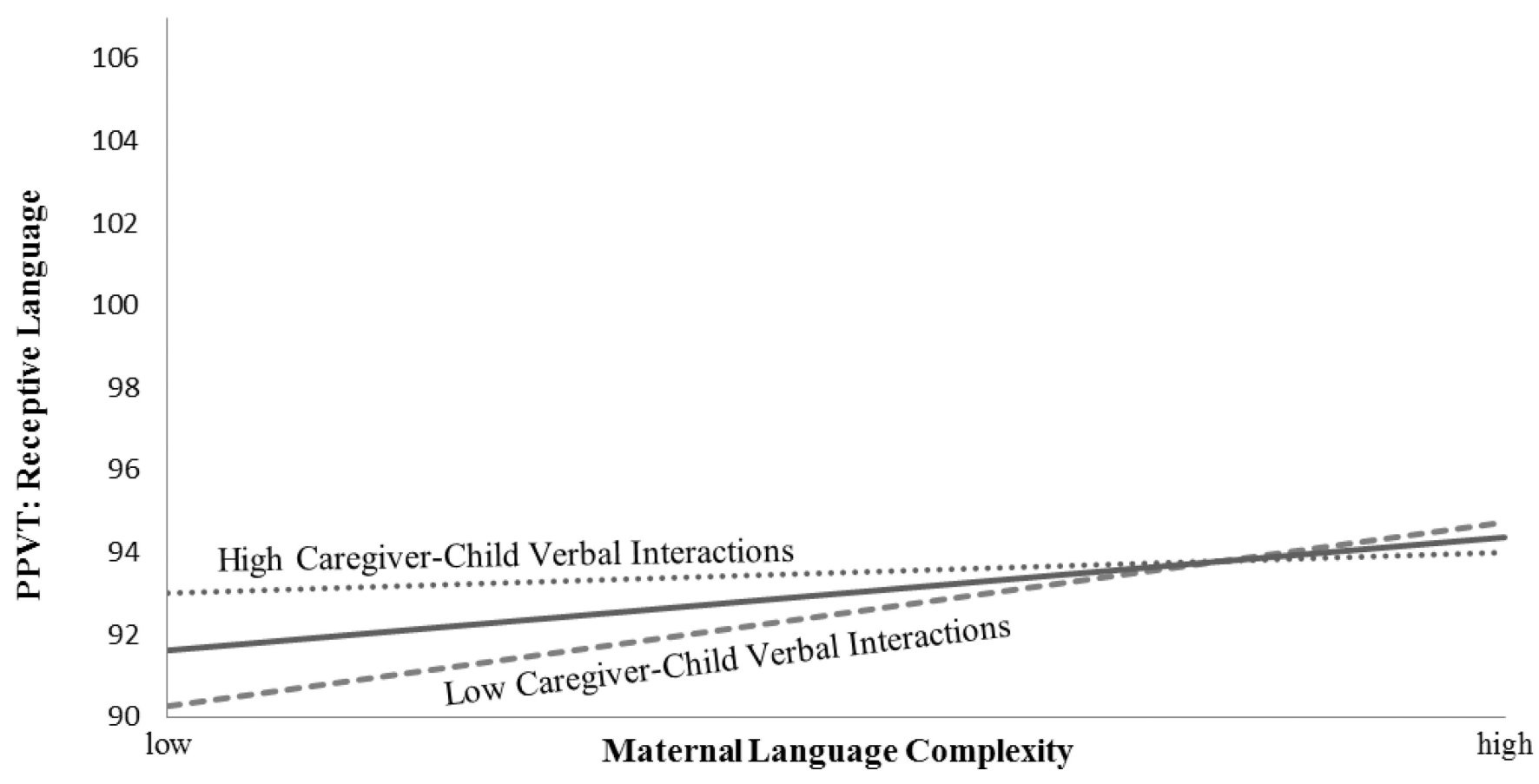

Figure 3.

Predicting Receptive Language at PreK: Maternal Language Complexity $\times$ Caregiver-Child Positive Verbal Interactions 
Table 1

Sample Descriptive Statistics $(\mathrm{n}=433)$

\begin{tabular}{|c|c|c|c|c|}
\hline \multirow[b]{2}{*}{ Variable } & \multicolumn{2}{|c|}{36 Months } & \multicolumn{2}{|c|}{48 Months } \\
\hline & $M$ & $S D$ & $M$ & $S D$ \\
\hline \multicolumn{5}{|l|}{ Social and family context } \\
\hline Region/location (\% in PA) & 31.18 & & 31.18 & \\
\hline Income-to-needs ratio & 2.06 & 1.48 & 1.80 & 1.22 \\
\hline Maternal education (years) & 13.25 & 1.90 & 13.38 & 1.89 \\
\hline Maternal age (years) & 29.21 & 6.58 & 30.40 & 6.92 \\
\hline Marital status (\% married/partnered) & 54.50 & & 60.00 & \\
\hline Children $<18$ in household & 2.26 & 1.17 & 2.36 & 1.17 \\
\hline Home environment quality (HOME at 36 months) & 0.80 & 0.16 & & \\
\hline \multicolumn{5}{|l|}{ Child characteristics } \\
\hline Age (months) & 36.95 & 1.61 & 59.89 & 3.32 \\
\hline Gender (\% female) & 49.19 & & 49.51 & \\
\hline Race (\% African American) & 52.19 & & 51.71 & \\
\hline Negative temperament & 6.52 & 1.03 & 6.44 & 1.12 \\
\hline 15-mo mental development index (Bayley) & 95.90 & 11.01 & 95.90 & 11.01 \\
\hline 15-mo language/speech composite (CSBS) & 10.29 & 3.28 & 10.29 & 3.28 \\
\hline \multicolumn{5}{|l|}{ Child care characteristics } \\
\hline Number of hours in care/week & 35.66 & 14.04 & 28.04 & 11.38 \\
\hline Number of time points in care & 2.86 & 1.11 & 3.73 & 1.19 \\
\hline \multicolumn{5}{|l|}{ Child care type (\%) } \\
\hline Informal care & 41.80 & & 6.65 & \\
\hline Formal, center-based care & 58.20 & & 93.35 & \\
\hline Child care quality (HOME) & 0.77 & 0.12 & & \\
\hline Child care quality (CLASS Instructional Support) & & & 2.47 & 0.96 \\
\hline \multicolumn{5}{|l|}{ Maternal language input } \\
\hline Diversity & 0.02 & 0.86 & & \\
\hline Number of different words & 114.36 & 38.59 & & \\
\hline Number of question words & 29.30 & 16.57 & & \\
\hline Time in seconds & 312.21 & 125.98 & & \\
\hline Complexity & 0.00 & 0.69 & & \\
\hline Mean length in utterance & 4.06 & 0.74 & & \\
\hline Complex conjunctions & 13.78 & 14.68 & & \\
\hline Mean turn length & 12.48 & 15.51 & & \\
\hline \multicolumn{5}{|l|}{ Child care interactions } \\
\hline Caregiver-child verbal interactions & 0.55 & 0.38 & & \\
\hline \multicolumn{5}{|l|}{ Outcome variables } \\
\hline Expressive language (PLS) & 99.35 & 15.51 & & \\
\hline Receptive language (PPVT) & & & $92.99^{1}$ & 14.87 \\
\hline
\end{tabular}

Note. 
${ }^{1}$ Assessed at pre-K. 


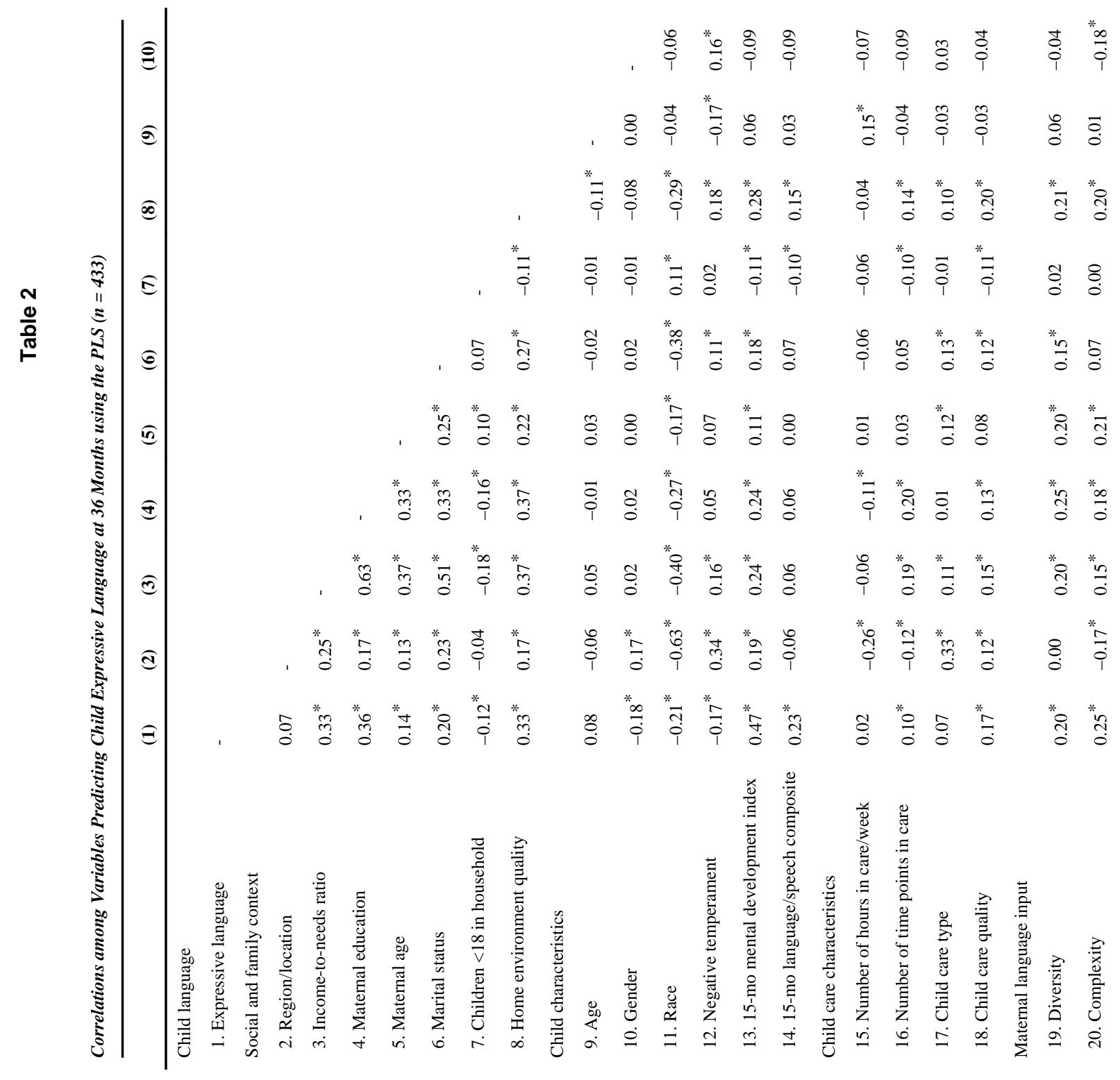




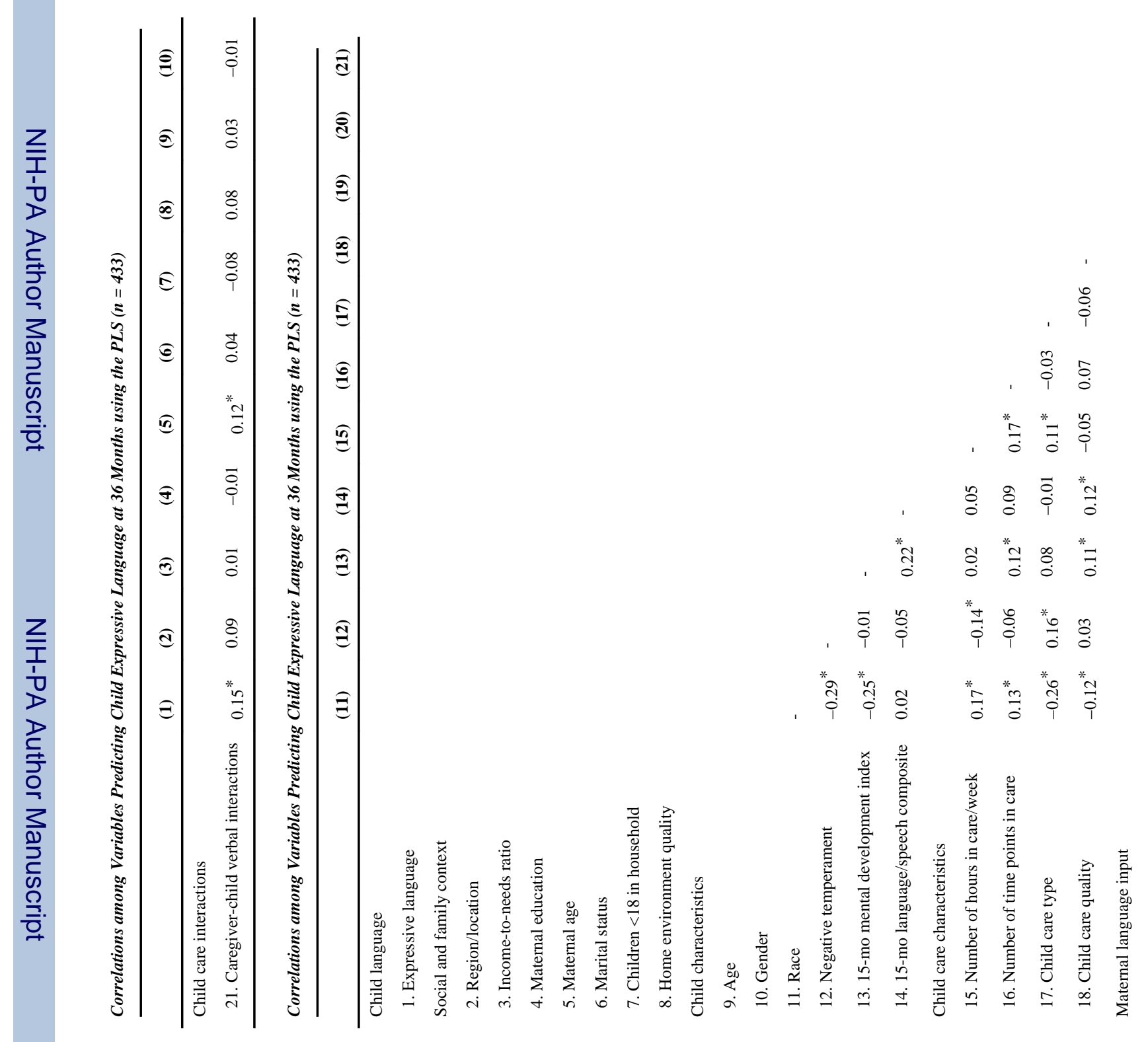

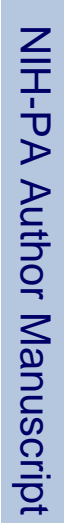




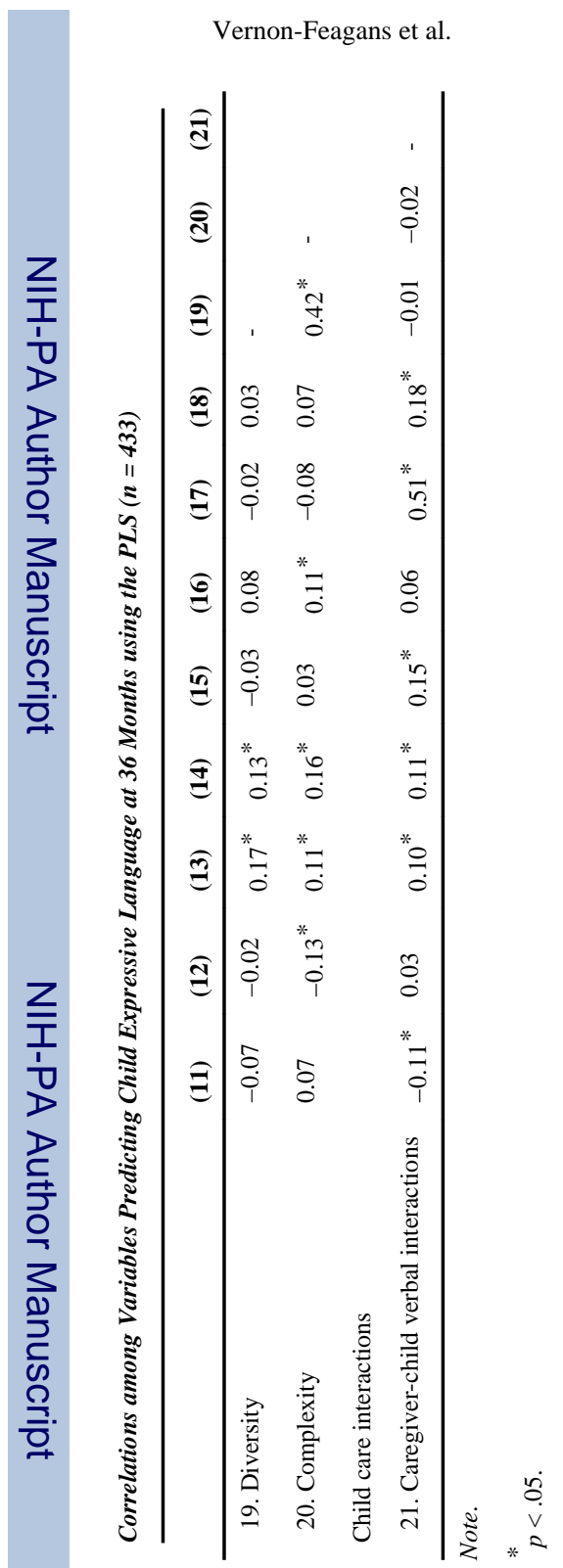

Page 30

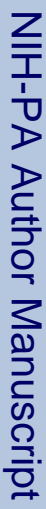

Early Child Res Q. Author manuscript; available in PMC 2014 December 01. 


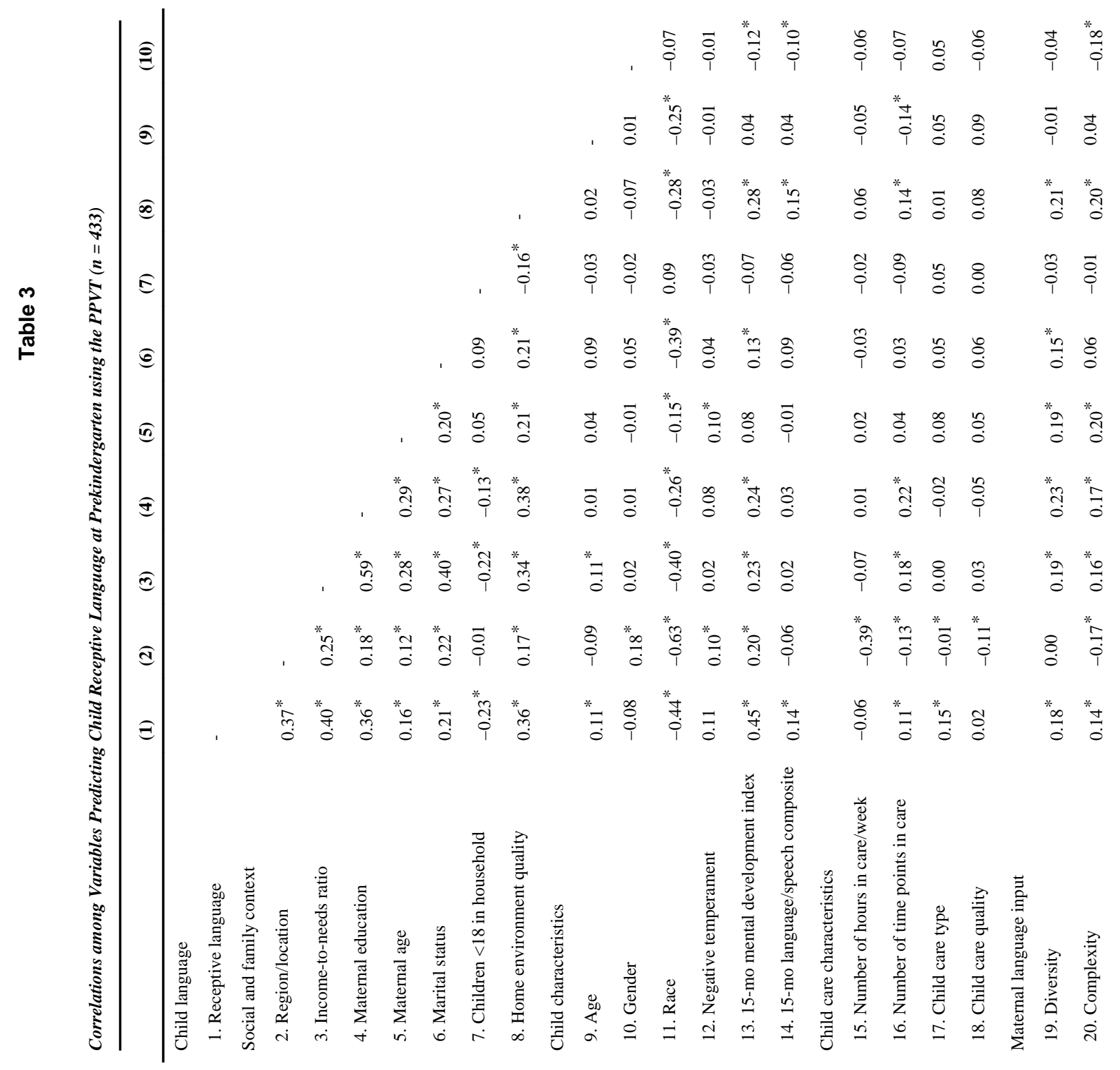











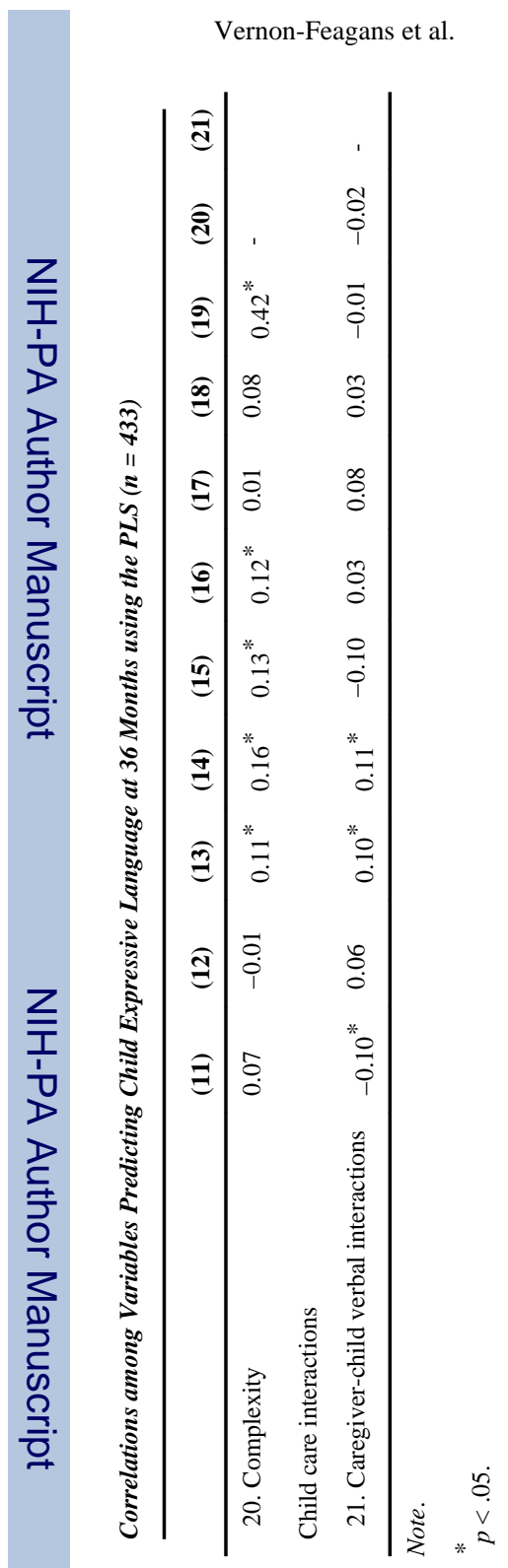

Page 33

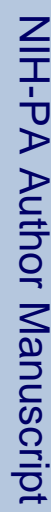

Early Child Res Q. Author manuscript; available in PMC 2014 December 01. 


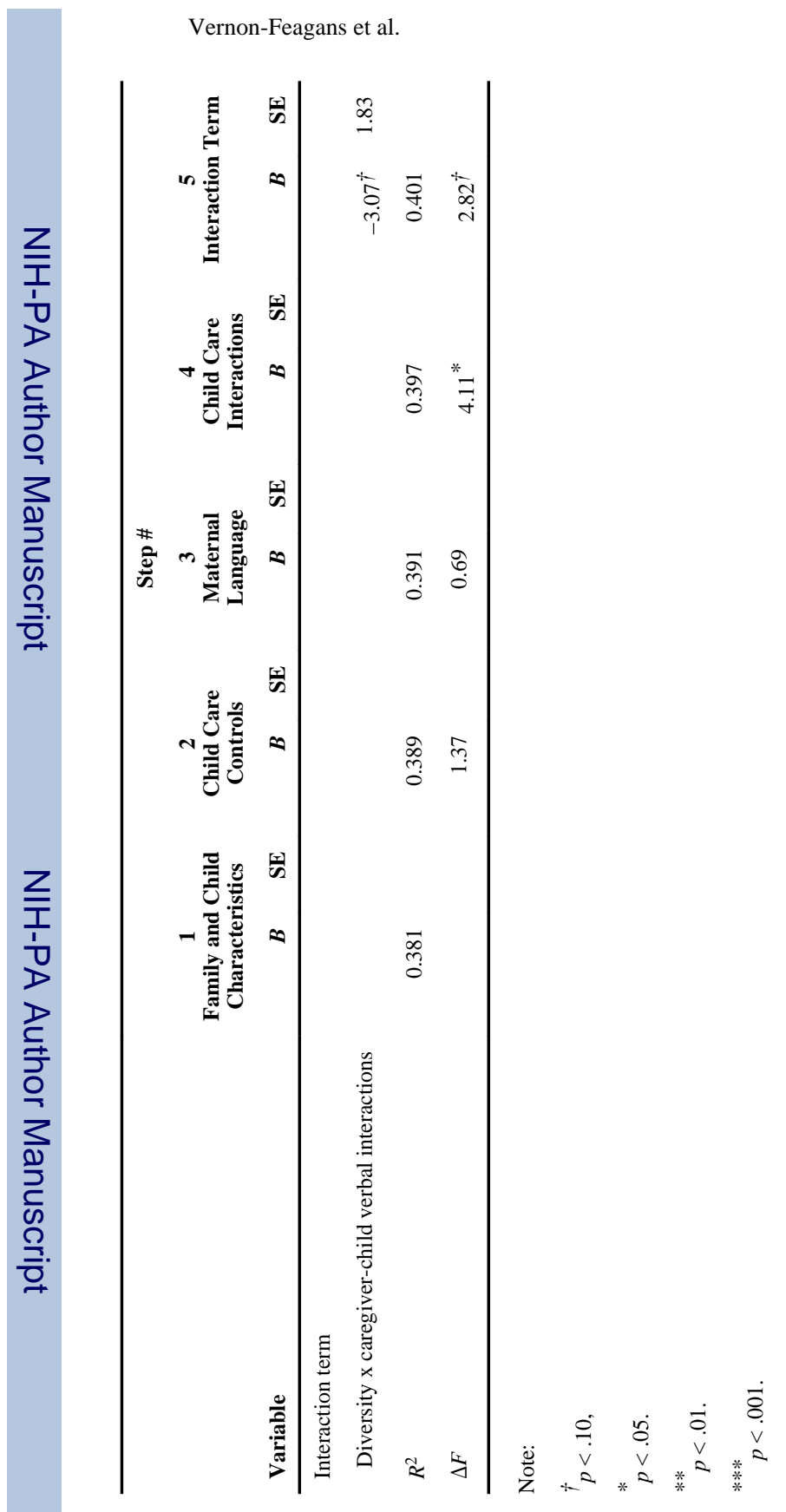

Early Child Res Q. Author manuscript; available in PMC 2014 December 01. 


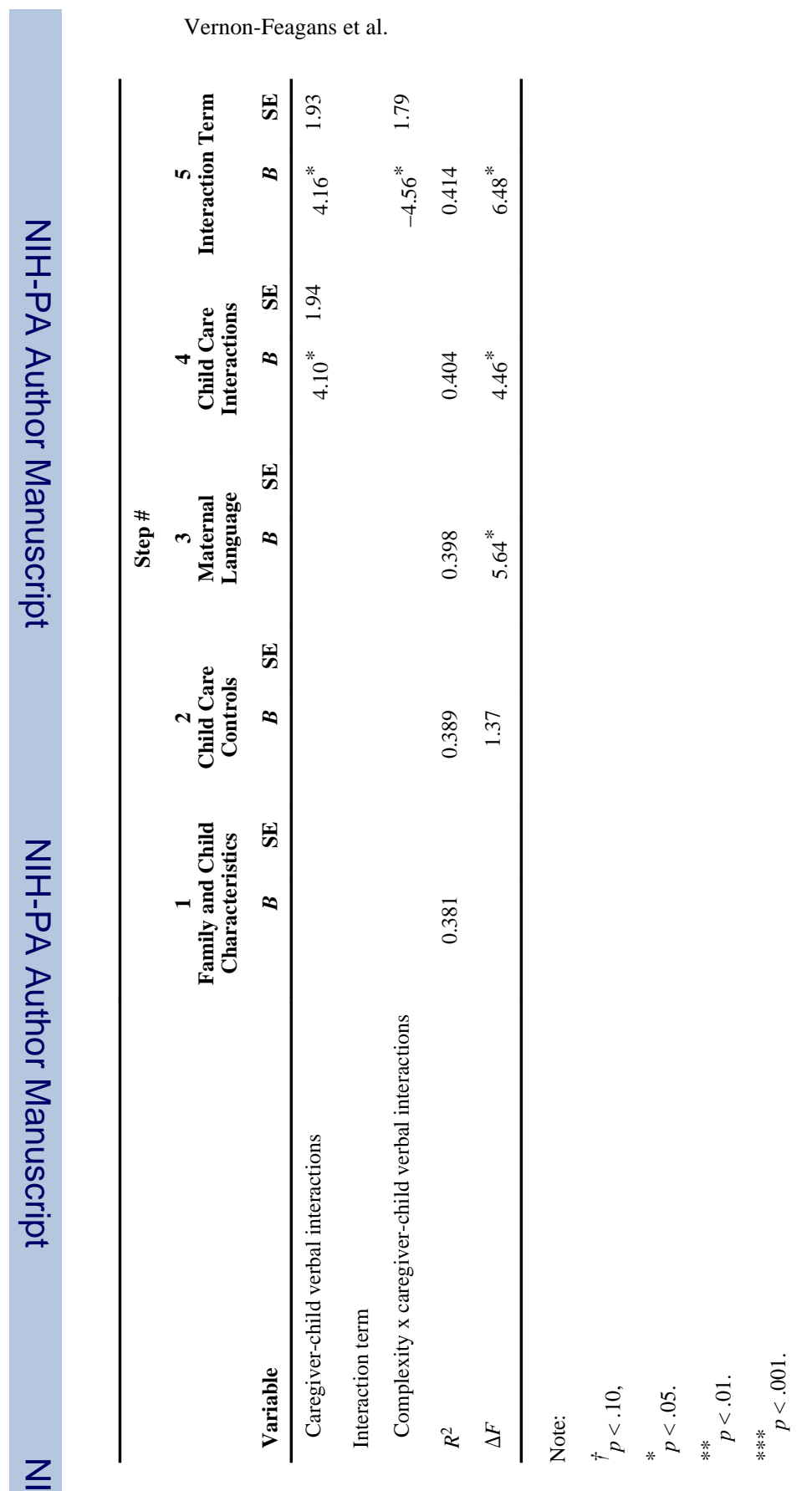

Early Child Res Q. Author manuscript; available in PMC 2014 December 01. 







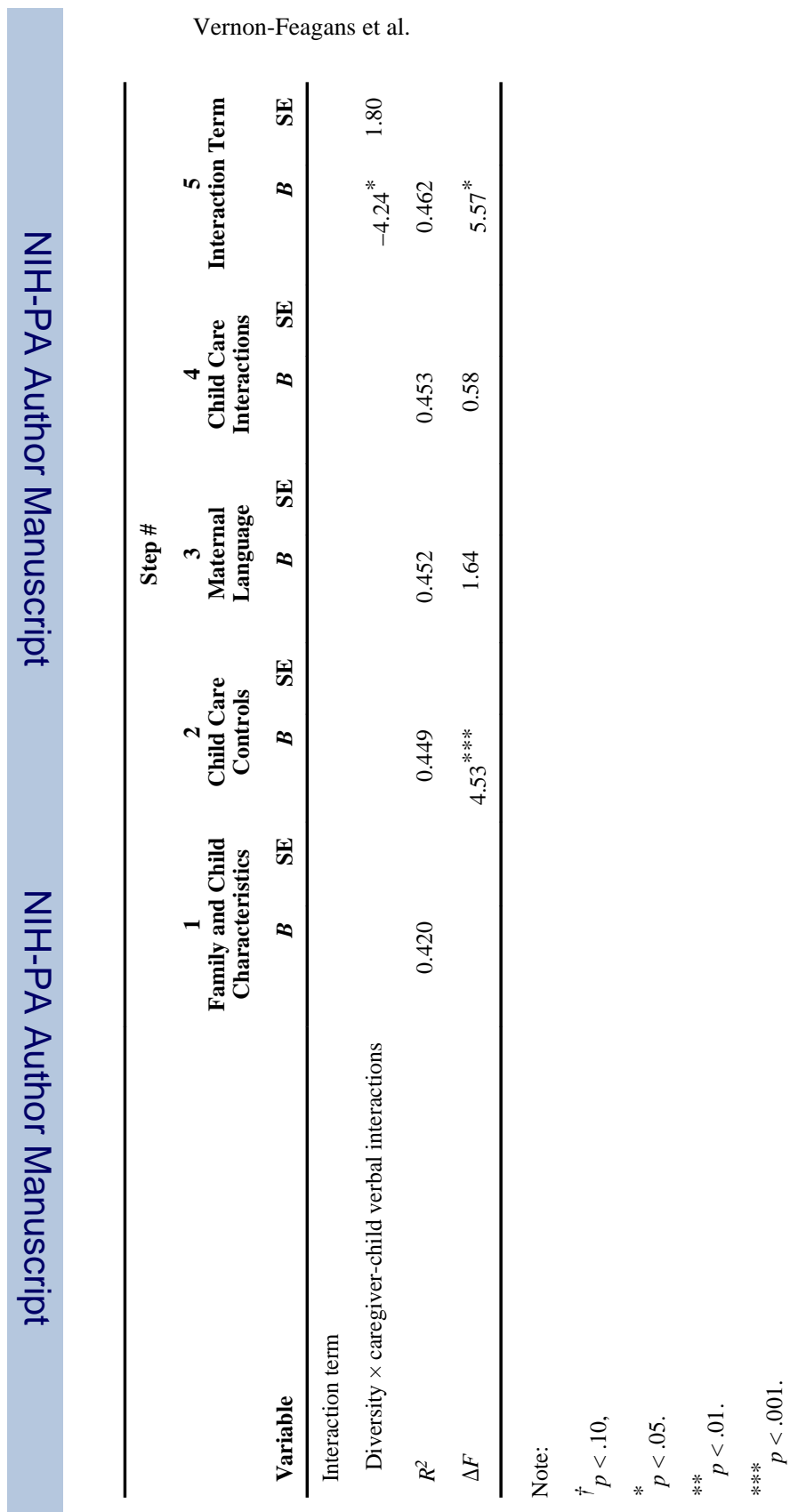

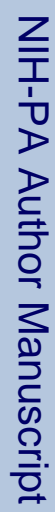

Early Child Res Q. Author manuscript; available in PMC 2014 December 01. 


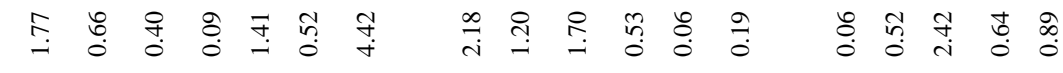

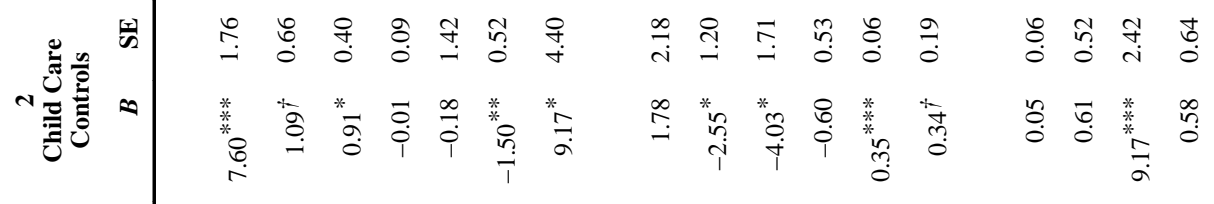

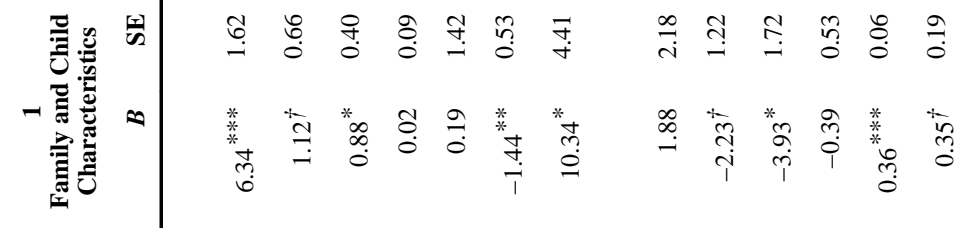






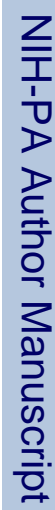

Early Child Res Q. Author manuscript; available in PMC 2014 December 01. 